Article

\title{
Energy, Exergy and Economic Analyses of a Combined Heating and Power System with Turbine-Driving Fans and Pumps in Northeast China
}

\author{
Ximei Li@, Jianmin Gao *, Yaning Zhang, Yu Zhang, Qian Du®, Shaohua Wu and Yukun Qin \\ School of Energy Science and Engineering, Harbin Institute of Technology, Harbin 150001, China; \\ lixmhit@163.com (X.L.); ynzhang@hit.edu.cn (Y.Z.); zhang.y@hit.edu.cn (Y.Z.); duqian@hit.edu.cn (Q.D.); \\ wush@hit.edu.cn (S.W.); qinyk@hit.edu.cn (Y.Q.) \\ * Correspondence: yagjm@hit.edu.cn; Tel.: +86-0451-8641-2618
}

Received: 15 January 2020; Accepted: 13 February 2020; Published: 17 February 2020

check for updates

\begin{abstract}
The combined heating and power (CHP) system with turbine-driving fans and pumps is more efficient and economical in meeting heat demand in cold areas, however, there are no detailed studies that investigate its thermodynamic performance, improvement possibilities and economy. In this paper, the energy, exergy and economic analysis of a CHP system with turbine-driving fans and pumps operated in Northeast China were conducted to provide insights into improvement options. It is revealed that the boiler is the main source of exergy destruction, followed by the steam-water heat exchangers (SWHE), temperature and pressure reducer (TPR), turbines, and deaerator. The energy and exergy efficiencies of the system are $89.72 \%$ and $10.07 \%$, while the boiler's are $84.89 \%$ and $30.04 \%$. The thermodynamic performance of the boiler and turbines are compared with other studies, and the inefficiencies of major components are analyzed and some advice for further improvement is given. As the reference state changes, the main conclusions stay the same. The turbine-driving mode saves an electricity cost of 16,654.08 yuan on 15 December 2018. The effect of electricity price and on-grid price on the saved daily electricity cost is investigated and it proves that the turbine-driving mode is more economical in China.
\end{abstract}

Keywords: turbine-driving; CHP system; thermodynamic performance; economic; electricity cost

\section{Introduction}

Energy consumption is increasing dramatically with the explosive population growth, urbanization, industrialization, and technical advancement. This fast-upward situation brings about some vital issues such as energy crisis and environmental contamination. As the energy demand is still dominated by fossil energy, solving the contradiction between fossil energy consumption and environmental pollution can be achieved mainly in two ways: growing alternative energy resources, especially renewable ones, and improving the energy utilization efficiencies of fossil fuels [1]. The latter is a cheaper, faster and easier way to realize this task.

For improving the energy utilization efficiencies of fossil fuels, the thermodynamic performances of equipment and systems need to be evaluated. Usually, the thermodynamic performances of equipment and systems are investigated by energy standards based on the first law of thermodynamics. In the past several decades, exergy analysis has been developed based on the second law of thermodynamics and proved as an effective way to evaluate the thermodynamic performances of systems as it can not only detect the causes, location, and magnitudes of irreversibility in the system but also highlight the improvement potential of components [2]. These points are the major difference between exergy analysis and energy analysis. Therefore, performing exergy and energy analyses together for a system can provide an all-round depiction of the system characteristics. 
Energy and exergy analyses are widely used and have been applied to many fields such as thermal power plants [3-7], hybrid energy systems [8-11], polygeneration systems [12-16], the manufacturing sector [17-19], the food processing industry [20-23] and district heating systems [24-27] to explore better energy production, transmission, and utilization solutions and determine the links to improvement. Among them, combined heating and power (CHP) is one of the important ways to optimize energy utilization, which has considerable advantages, including high efficiency in use and conversion of primary energy, improving the economy of fuels, creating competitive conditions for thermal power market and reducing greenhouse gas emissions. In 2018, CHP accounted for nearly $80 \%$ in the global urban heating market [28]. In China, CHP is mainly used to meet heating demand. It's expected that by the end of 2020, the central heating rate of CHP in large and medium-sized cities in North China will be more than 60\% [29]. CHP has been developed to a certain scale, but it is far from meeting the actual demand. Thus, many researchers are spurred to carry out performance analysis and efficiency optimization for CHP and relevant systems to further improve their efficiency and satisfy the growing heating demand. For an existing CHP system, Ahmadi et al. [14] performed energy, exergy and environmental analyses, and it was revealed that the boilers have the highest exergy destruction, followed by the steam pressure reduction stations and turbo-generators. They recommended that, instead of the boilers, a gas turbine may perform better, and a heat recovery steam generator may be also needed for improvement. Heberle and Brüggemann [30] were interested in the exergy performance of a geothermal power plant. They found that, compared with a power generation, the exergy efficiency of the plant with a CHP technology could be greatly improved. Kanoglu and Dincer [31] conducted energy and exergy analyses for many building CHP systems and investigated how the energy and exergy efficiencies changed with the fluctuation of water temperature, steam pressure and some other parameters. The results indicated that systems with diesel and geothermal have an advantage in exergy efficiency over those with steam and gas turbines. Wang and Yang [32] proposed a hybrid combined cooling, heating and power (CCHP) system based on using biomass and solar energy and analyzed their complementarity to promote the energy efficiency of the system. It was revealed that the biomass subsystem contributed to the primary energy ratio and exergy efficiency of the total system more than the solar subsystem. Al-Sulaiman et al. [33] evaluated the exergy level of a CCHP system and found that the main exergy destruction occurred in the biomass combustor and the organic Rankine cycle evaporator. The energy and exergy efficiencies were both increased by using CCHP when compared with only using power generation, and as the temperature and pressure varied, the heating-cogeneration and CCHP cases varies less in the exergy analysis than the power generation and cooling-cogeneration ones. Khaljani et al. [34] performed thermodynamic assessment of a CHP cycle and revealed that the combustion chamber was the main exergy destruction component, and the heat recovery steam generator stand the next, then is gas turbine. They also carried out the exergo-economic analysis for the cycle and found that the overall exergo-economic factor was $10.59 \%$.

It is clear that many efforts and trials have been made in improving and innovating CHP systems by energy, exergy and economic analyses. However, as the feedwater pump, induced draft fan and desulfurization circulating pump are important auxiliary equipment in CHP systems, their power consumption represents a huge burden for heating plants. With stricter rules and regulations about emissions, the power consumption of induced draft fan and desulfurization circulating pump will escalate. Thus, researchers have been further motivated to look for ways to innovate the CHP system. Considering some thermal power plants use the small turbines to drive the feedwater pump and induced draft fan, it may be feasible to develop a CHP system using turbines to drive pumps and induced draft fans for heating plants. In this case, the trigeneration of work, heat, and power can be realized to promote energy utilization and the contradiction between the growing heat demand and surplus power can also be relieved. However, to the authors' knowledge, few in any studies of such a CHP system have been reported, nor further performance analysis.

In this paper, a CHP system using turbines to drive a feedwater pump, desulfurization circulating pump and induced draft fans was proposed, and the energy, exergy and economic performances were 
determined based on the system's operational data to figure out the breakthrough points for energy conservation, which will lay the foundations for future optimization studies.

\section{Materials and Methods}

\subsection{System Description}

The investigated CHP system was constructed in 2016 in Shenyang, Northeast China, in which turbines not only can be used to generate power but also can be used to drive fans and pumps. The system cooperates with another two 90 MW hot water boilers to satisfy the thermal demand of residents during the heating period from 1 November to 31 March every year. The real system is very complex and Figure 1 depicts a schematic representation of the system. As it shows, steam turbines, instead of electricity, are applied in the system to drive high energy-consumption equipment, including a feedwater pump, a desulfurization circulating pump, a steam boiler's and two hot water boilers' induced draft fans, to reduce the energy consumption and operation costs, and the configurations of the induced draft fans and pumps driven by turbines are shown in Figure 2 and efficiencies of the transmission processes are assumed as $100 \%$. As the major part of the system, the steam boiler is a chain-grate boiler with a mass flow rate of $130 \mathrm{t} / \mathrm{h}$ and a rated pressure of $1.3 \mathrm{MPa}$. The deaerator is an atmospheric rotary membrane thermal deaerator with a working pressure of $0.12 \mathrm{MPa}$. The steam turbines used in the system are all backpressure turbines, the inlet steams of which are the fresh steam from the boiler, and the exhaust steams enter the steam-water heat exchangers.

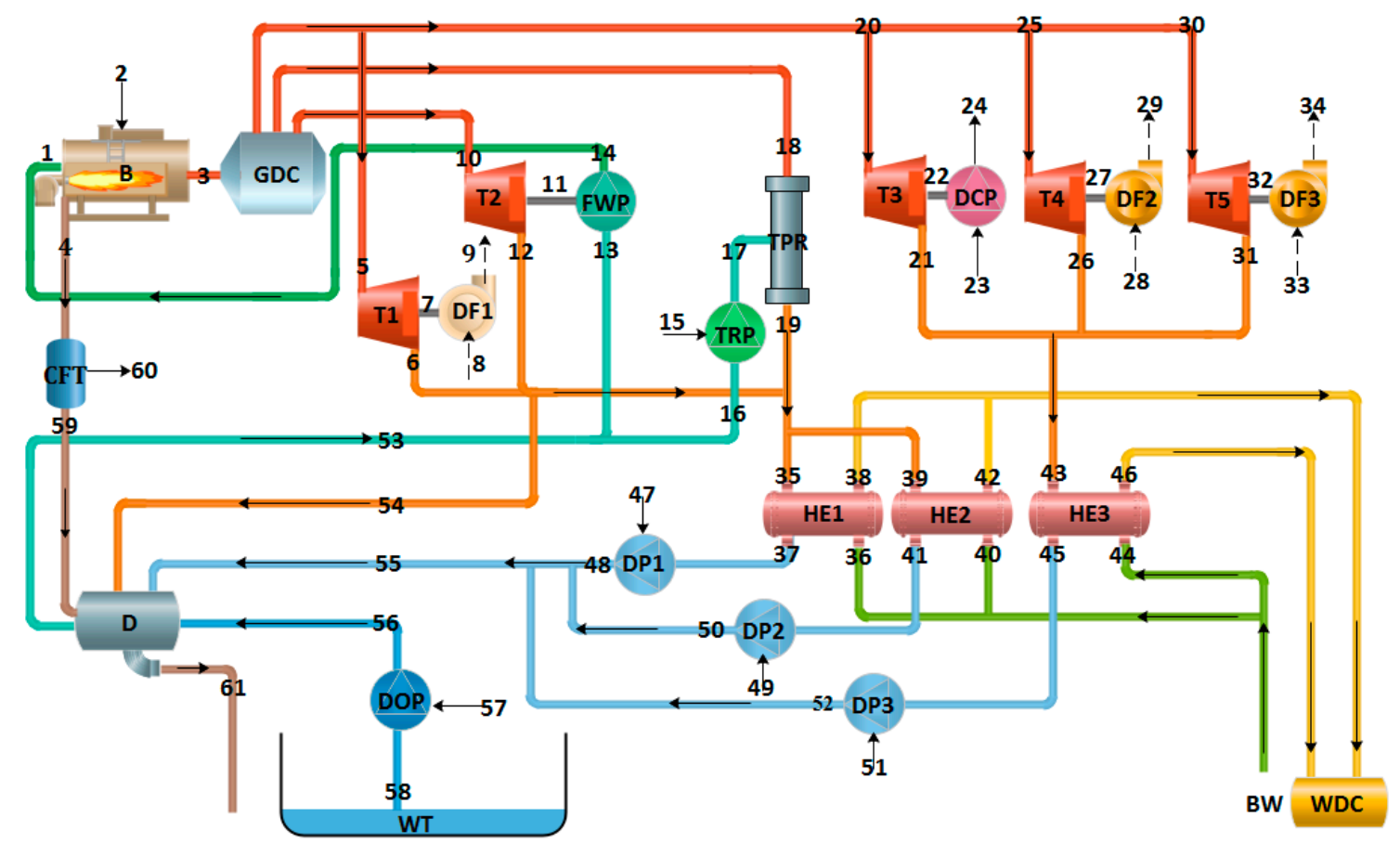

Figure 1. The layout of the CHP system with turbine-driving technology. Key: B-boiler; GDC-gas-distributing cylinder; T-turbine; DF-induced draft fan; FWP-feedwater pump; TPR-temperature and pressure reducer; DP-drain pump; DCP-desulfurization circulating pump; TRP-temperature reduction pump; HE-steam water heat exchanger; DOP-deoxygenation pump; D-deaerator; CFT-continuous blowdown flash tank; BW-back water; WT-water tank; WDC-water distributing cylinder. 


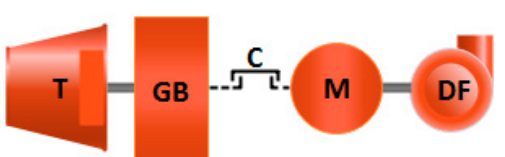

(a) Turbine-driving induced draft fan

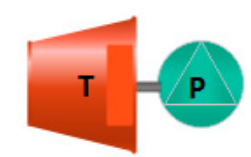

(b) Turbine-driving pump

Figure 2. Configuration of the turbine-driving induced draft fan and pumps. Key: GB-gear box; C-coupling; M-motor; P-pump.

The working process of the system (S) is shown by the arrowed lines in Figure 1. The fuel used in the system is Huolin River lignite, and its properties are listed in Table 1. Fuel (2) is burned in the steam boiler (B) to heat the feed water (1) from the deaerator (D) into steam (3). At the same time, sewage (4) is produced and recovered by the continuous blowdown flash tank (CFT), the steam generated by which flows into the deaerator. Steam from the boiler is distributed through a gas-distributing cylinder (GDC) to a temperature and pressure reducer (TPR) and five turbines (T1, T2, T3, T4, T5) which are used to drive a steam boiler's induced draft fan (DF1), a feedwater pump (FWP), a desulfurization circulating pump (DCP) and two hot water boilers' induced draft fans (DF2 and DF3), respectively. Steam entering the TPR is cooled by the deoxidized water pumped by the temperature reduction pump (TRP) and then is mixed with the exhaust steam of T1 and T2. Afterward, part of it is the heating steam of the deaerator (D), and the rest flows into the steam-water heat exchangers (HE1 and HE2) to heat the backwater (BW) of the pipeline and then is recovered to the deaerator by drain pumps (DP1 and DP2). The exhaust steam of T3, T4 and T5 enters another steam-water heat exchanger (HE3) to heat the BW and then is also recovered to the deaerator by the drain pump (DP3). The hot water from the three steam-water heat exchangers flows to a water-distributing cylinder (WDC) to satisfy the thermal demand of residents. The condensate water recovered from steam-water heat exchangers pumped by DP1, DP2, and DP3 along with the supplementary water pumped by the deoxygenation pump (DOP) from the water tank (WT) constitute inlet water of the deaerator and they are deaerated to be the feed water of the boiler and the cooling water of TPR. At this point, a cycle of water and steam is completed in the system. In this situation, the turbines are fully used to drive fans without generating power.

Table 1. Ultimate analysis of Huolin River lignite.

\begin{tabular}{ccc}
\hline Dry Ash-Free Basis & Unit & Value \\
\hline $\mathrm{C}_{\text {daf }}$ & $\%$ & 66.72 \\
$\mathrm{H}_{\text {daf }}$ & $\%$ & 4.59 \\
$\mathrm{O}_{\text {daf }}$ & $\%$ & 26.67 \\
$\mathrm{~N}_{\text {daf }}$ & $\%$ & 1.07 \\
$\mathrm{~S}_{\text {daf }}$ & $\%$ & 0.95 \\
$\mathrm{LHV}_{0}{ }^{1}$ & $\mathrm{~kJ} \cdot \mathrm{kg}^{-1}$ & 15,446 \\
\hline
\end{tabular}

${ }^{1}$ Low heat value.

\subsection{Data Preparation}

The data used in the analysis are the actual operational data recorded by the distributed control system (DCS) of the heating plant on 15 December 2018. On this day, the system runs smoothly and the load changes little. And the recorded data are processed by averaging and then applied to the throughout assessment of the system.

\subsection{Analytical Methods}

For the analyses, some assumptions were made:

(1) A steady-state operational condition is assumed for the whole process.

(2) The kinetic and potential exergies of flows are neglected. 
(3) The fresh air and flue gas are considered as ideal gases.

(4) The pressure losses in piping and ducts are neglected.

(5) The basic analysis is based on the reference state of $298.15 \mathrm{~K}$ and $0.10 \mathrm{MPa}$.

(6) The standard molar fractions of species in the reference state are taken according to those of Szargut et al. [35].

\subsubsection{Energy Analysis}

The specific energy of the fuel is taken as its low heat value $\left(\mathrm{LHV}_{0}\right)$ which is measured as $15,446 \mathrm{~kJ} / \mathrm{kg}$. The thermodynamic properties of water and steam are determined by IAPWS-IF97.

For a system, the total energy includes three parts: the energy induced by the mass flow, the work exchanged with the outside and the energy lost to the ambient, so the energy balance can be expressed by Equations (1) and (2):

$$
\dot{E} n_{\text {in }}+\dot{W}_{\text {in }}=\dot{E n_{\text {out }}}+\dot{Q}_{1}
$$

where, $E n$ is the energy rate of the system, $\mathrm{kW} ; W$ is the work rate, $\mathrm{kW} ; \dot{Q}$ is the exchanged heat rate with the ambient, $\mathrm{kW}$; the subscript in, out and 1 mean inflows, outflows, and loss of the system.

$$
\sum_{i=1}^{n} \dot{m}_{\mathrm{in}, i} e n_{\mathrm{in}, i}+\sum_{j=1}^{j} \dot{W}_{j}=\sum_{k=1}^{k} \dot{m}_{\mathrm{out}, k} e n_{\mathrm{out}, k}+\dot{Q}_{1}
$$

where, $\dot{m}$ is the mass flow rate of one stream, $\mathrm{kg} / \mathrm{s}$; $e n$ is the specific energy rate, $\mathrm{kJ} / \mathrm{kg}$; the number $i, j$, and $k$ mean the $i$-th flow into the system, $j$-th work into the system and $k$-th flow out of the system.

The effective power of the induced draft fan is calculated by Equation (3):

$$
\dot{P_{\mathrm{e}}}=\frac{\dot{q_{v} p}}{1000}
$$

where, $\dot{P}_{\mathrm{e}}$ is the power of the induced draft fan, $\mathrm{kW} ; \dot{q}_{v}$ is the volume flow of the induced draft fan, $\mathrm{m}^{3} / \mathrm{s}$; and $p$ is the total pressure, $\mathrm{Pa}$. At the operational conditions, the total pressure of DF1 is $5660 \mathrm{~Pa}$, and for DF2 and DF3, both are $5426 \mathrm{~Pa}$.

The energy efficiency of one component or a system is defined as the ratio of the gained energy to the paid energy and is illustrated as Equation (4):

$$
\eta_{\text {en }}=\frac{\dot{E} n_{\text {gain }}}{\dot{E} n_{\text {pay }}} \times 100 \%
$$

The energy balance and the energy efficiency of every component in the CHP system are shown in Appendix A (Table A1). Note that the energy efficiencies of all steam turbines are designed as $78.50 \%$ and hardly change with the operational conditions.

For the whole system, energy efficiency is expressed by Equation (5):

$$
\eta_{\mathrm{en}, \mathrm{S}}=\frac{\dot{E n_{41}+\dot{E n_{45}}+\dot{E} n_{53}}}{\dot{E n_{2}}+\dot{W}_{18}+\dot{E n_{39}}+\dot{E} n_{43}+\dot{E} n_{51}+\dot{W}_{54}+\dot{W}_{56}+\dot{W}_{60}+\dot{E} n_{67}+\dot{W}_{66}} \times 100 \%
$$

\subsubsection{Exergy Analysis}

The exergy rates of the fuel and the flue gas consist of physical exergy and chemical exergy and can be expressed as Equation (6):

$$
\dot{E x}=\dot{E x} \dot{x}^{\mathrm{ph}}
$$


where, Ex is the exergy rate, $\mathrm{kW}$; and the superscripts ch and ph mean the chemical exergy and physical exergy, $\mathrm{kW}$.

No attention is paid to the physical exergy of the lignite because of its minor effect on the total exergy, while the physical exergy of the flue gas is calculated as Equation (7):

$$
\dot{E x}^{\mathrm{ph}}=\dot{m}\left[c_{p}\left(T-T_{0}-T_{0} \ln \left(\frac{T}{T_{0}}\right)\right)+R T_{0}\left(\frac{P}{P_{0}}\right)\right]
$$

where, $T$ is the temperature of the flue gas, $\mathrm{K} ; \mathrm{P}$ is the pressure of flue gas, $\mathrm{MPa}$; the subscript 0 means the reference state.

The specific heat capacity of the flue gas $c_{p}$ is calculated by Equation (8):

$$
c_{p}=\sum_{i=1}^{n} y_{i} c_{p, i}
$$

where, $i$ is the $i$-th component in flue gas, and $y$ is the mole fraction of one component in the total flue gas.

The chemical exergy rate of the fuel is computed by Equation (9):

$$
\dot{E x} \dot{c h}^{\text {ch }}=\dot{m} e x^{\text {ch }}=\dot{m} L H V_{0}\left(1.0064+0.1519 \frac{H_{\mathrm{daf}}}{C_{\mathrm{daf}}}+0.0616 \frac{O_{\mathrm{daf}}}{C_{\mathrm{daf}}}+0.0429 \frac{N_{\mathrm{daf}}}{C_{\mathrm{daf}}}\right)
$$

where, $e x$ is the specific exergy rate, $\mathrm{kW}$.

The chemical exergy rate of the flue gas is calculated by Equation (10):

$$
\dot{E x}^{\mathrm{ch}}=\dot{m} e x^{\mathrm{ch}}=\dot{m} n\left(\sum_{i} y_{i} \varepsilon_{i}+\bar{R} T_{0} \sum_{i} y_{i} \ln \left(y_{i}\right)\right)
$$

where, $\varepsilon$ is the standard chemical exergy, $\mathrm{kJ} / \mathrm{mol} ; \bar{R}$ is the universal gas constant, $8.314 \mathrm{~J} /(\mathrm{kg} \cdot \mathrm{K})$.

It is assumed that the composition of flue gas doesn't change before and after flowing through a component. So, changes in the chemical exergy of the flue gas are disregarded, and the exergy change only consists of the change of the physical. The composition of the flue gas is shown in Table 2.

Table 2. Composition of flue gas.

\begin{tabular}{ccc}
\hline Composition & Unit & Value \\
\hline $\mathrm{CO}_{2}$ & $\%$ & 12.25 \\
$\mathrm{O}_{2}$ & $\%$ & 7.95 \\
$\mathrm{CO}$ & $\%$ & 0.03 \\
$\mathrm{~N}_{2}$ & $\%$ & 79.77 \\
\hline
\end{tabular}

The physical exergy rate of water and steam is calculated by Equation (11):

$$
\dot{E x}^{\mathrm{ph}}=\dot{m} e x=\dot{m}\left[h-h_{0}-T_{0}\left(s-s_{0}\right)\right]
$$

where, $\mathrm{h}$ is the enthalpy of a stream, $\mathrm{kJ} / \mathrm{kg}$; $\mathrm{s}$ is the entropy, $\mathrm{kJ} /(\mathrm{kg} \cdot \mathrm{K})$.

Exergy loss caused by heat transfer is calculated by Equation (12):

$$
\dot{E x_{1}}=\dot{Q}_{1}\left(1-\frac{T_{0}}{T}\right)
$$


The exergy balance for one component or a system can be written as Equations (13) and (14):

$$
\begin{gathered}
\dot{E} x_{\mathrm{in}}+\dot{W}=\dot{E} x_{\mathrm{out}}+\dot{E} x_{1}+\dot{E} x_{\mathrm{d}} \\
\sum_{i=1}^{n} \dot{m}_{\mathrm{in}, i} e x_{\mathrm{in}, i}+\sum_{j=1}^{n} W_{j}=\sum_{k=1}^{n} \dot{m}_{\mathrm{out}, k} e x_{\mathrm{out}, k}+\dot{E} x_{1}+\dot{E} x_{\mathrm{d}}
\end{gathered}
$$

where the subscript $d$ indicates the destroyed exergy.

Similarly, the exergy efficiency of one component or a system is defined as the ratio of the gained exergy to the spent exergy, as shown by Equation (15):

$$
\eta_{\text {ex }}=\frac{\dot{E} x_{\text {gain }}}{\dot{E} x_{\text {pay }}} \times 100 \%
$$

The exergy balance and the exergy efficiency of every component are listed in Appendix B (Table A2).

For the system, the exergy efficiency is expressed by Equation (16):

$$
\eta_{\mathrm{ex}, \mathrm{S}}=\frac{\dot{E x_{41}+\dot{E} x_{45}+\dot{E} x_{53}}}{\dot{E} x_{2}+\dot{W}_{18}+\dot{E} x_{39}+\dot{E} x_{43}+\dot{E} x_{51}+\dot{W}_{54}+\dot{W}_{56}+\dot{W}_{60}+\dot{E} x_{67}+\dot{W}_{66}} \times 100 \%
$$

The exergy improvement potential rate of each component is defined as Equation (17):

$$
\dot{E x_{\mathrm{p}}}=\left(1-\frac{\eta_{\mathrm{ex}}}{100}\right)\left(\dot{E} x_{\text {in }}-\dot{E} x_{\text {out }}\right)
$$

\subsubsection{Economic Analysis}

The economic analysis of the system is conducted by comparing the operational costs of turbine-driving mode with the electricity-driving mode. For the system, if auxiliaries are driven by power, then on 15 December 2018, the power consumption of feed water pump, desulfurization pump and the induced draft fans can be calculated by Equation (18):

$$
W=24 \times\left(\dot{W}_{7}+\dot{W}_{11}+\dot{W}_{22}+\dot{W}_{27}+\dot{W}_{32}\right)
$$

The cost of electricity is calculated by Equation (19):

$$
C=c_{\mathrm{e}} W
$$

where, $c_{\mathrm{e}}$ is the electricity price, yuan $/ \mathrm{kWh}$.

In the electricity-driving mode, turbines are used to generate power to be on-grid, and the income of electricity is shown by Equation (20):

$$
I=c_{\mathrm{o}} W
$$

where, $c_{\mathrm{O}}$ is the on-grid price, yuan $/ \mathrm{kWh}$.

Thus, the cost saved by the turbine-driving mode can be calculated by Equation (21):

$$
S=C-I
$$




\subsubsection{Uncertainty Analysis}

The uncertainty analysis of the data used in the system assessment is carried out by the methodology presented by Equation (22):

$$
U=\left[\left(\frac{\partial F}{\partial z_{1}} u_{1}\right)^{2}+\left(\frac{\partial F}{\partial z_{2}} u_{2}\right)^{2}+\cdots+\left(\frac{\partial F}{\partial z_{n}} u_{n}\right)^{2}\right]^{1 / 2}
$$

The results of uncertainties are acceptable as their values are within a range of $\pm 5 \%$.

\section{Results and Discussion}

The thermodynamic and economic performance of the CHP system with turbine-driving fans and pumps is studied by the energy, exergy and economic analyses in the study. The parameters of various streams are illustrated in Appendix C (Table A3), corresponding to their state numbers shown in Figure 1. Then the comprehensive energy and exergy analyses of the system are conducted based on the operational data and the results are shown in Appendix D (Table A4). The economic analysis is performed by comparing turbine-driving mode with the electricity-driving mode, and the effect of electricity price and on-grid price on the choice of operation mode is also studied.

\subsection{Energy Loss}

Figure 3 shows the ratio of each component's energy loss to the total. The boiler has the highest energy loss of $13,956.56 \mathrm{~kW}$, representing $75.19 \%$ of the total energy loss of $18,560.83 \mathrm{~kW}$. Such a huge amount of energy loss in the boiler is caused by various reasons, such as the energy loss of the flue gas to the ambient, incomplete combustion in the chamber, heat dissipation from the boiler body and so on. Among them, the flue gas energy loss may account for the most, as the temperature of flue gas is much higher than that of the ambient. The energy loss of the HEs (HE1, HE2, and HE3), TPR, turbines (T1, T2, T3, T4, and T5) and deaerator stand in the second, third, fourth and fifth, accounting for $12.73 \%, 6.32 \%, 2.92 \%$, and $1.27 \%$ of the total, respectively. for HEs, TPR, and deaerator, their energy losses are mostly due to the heat dissipation caused by the temperature difference between the surface and the environment. The energy losses of turbines, induced draft fans, and pumps are mainly caused by mechanical friction, but due to the higher temperature in turbines, their energy losses are much more significant. CFT is an efficient component and has no energy loss.

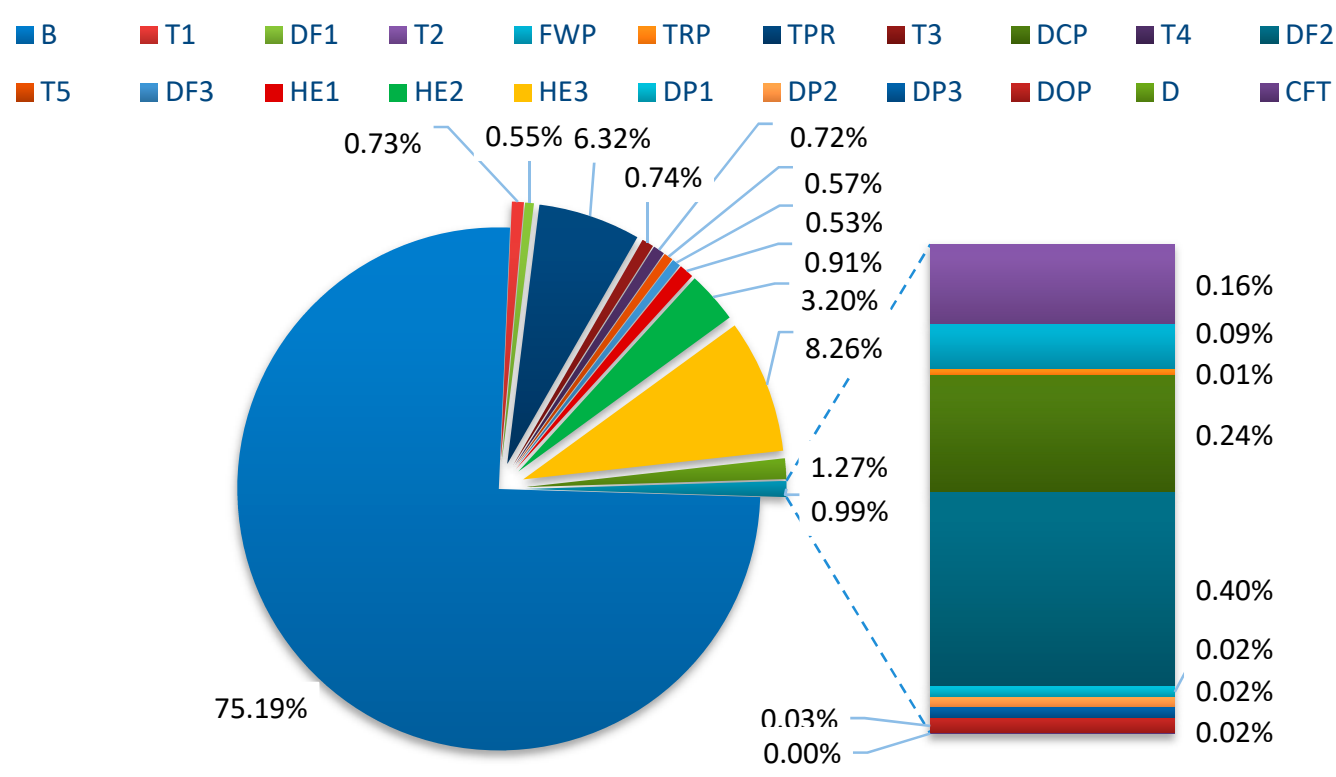

Figure 3. Percentage of each component's energy loss of the total energy loss. 


\subsection{Exergy Loss}

Figure 4 shows the ratio of each component's exergy loss to the total. From Equation (12), the exergy loss is closely related to the energy loss and the temperature of the heat source. The total exergy loss of the system is $4340 \mathrm{~kW}$ and the exergy loss of the boiler $(3243 \mathrm{~kW})$ is $74.72 \%$ of the total, which is far ahead of other exergy losses due to its much higher energy loss than others. The exergy loss of TPR $(11.22 \%)$ ranks the next, mainly for its high steam temperature. Due to the integration influence of energy loss and the heat source temperature, the exergy loss of HEs $(6.29 \%)$ is the third. For steam turbines (T1, $\mathrm{T} 2$, T3, T4, and T5), the proportions of exergy losses $(1.30 \%, 0.29 \%, 1.31 \%, 1.32 \%$, and $1.31 \%)$ are much higher compared with their energy losses because of their high steam temperatures. And the exergy loss of deaerator only shares a proportion of $1.14 \%$ for its lower temperature. minor energy losses of pumps and induced draft fans lead to the small exergy losses.

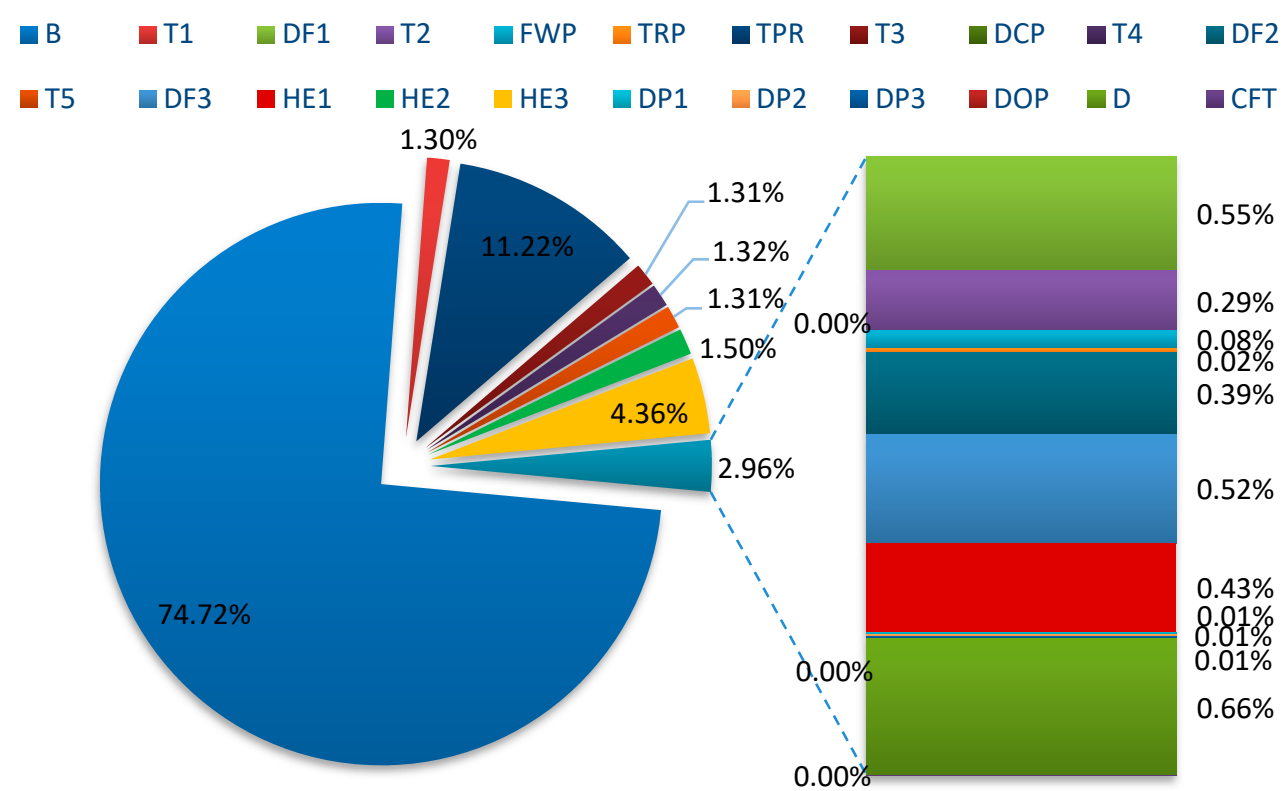

Figure 4. Percentage of each component's exergy loss of the total exergy loss.

\subsection{Exergy Destruction}

Figure 5 illustrates each components' percentile contribution to the total exergy destruction. Undoubtedly, the boiler has the highest exergy destruction of $73,789.79 \mathrm{~kW}$, which accounts for $79.23 \%$ of the total exergy destruction of $93,134.78 \mathrm{~kW}$.

Such high exergy destruction of the boiler is mainly induced by the chemical reactions within, especially the combustion part, because of the large temperature difference between the reactant and the chamber. What's more, the HEs, TPR, turbines, and deaerator rank the second, third, fourth, and fifth in exergy destruction, occupying $13.10 \%, 4.33 \%, 1.91 \%$ and $0.71 \%$ of the overall destruction, respectively. the exergy destructions of HEs, TPR, and deaerator are basically due to their severe heat and mass transfer process induced by high-temperature differences. Turbines' high exergy destructions are due to their low isentropic efficiency, which are resulted from their design parameters and the wear and tear of components. The exergy destruction ratios of other components are minor, accounting for only $0.72 \%$ of the total. 


\begin{tabular}{|c|c|c|c|c|c|c|c|c|c|}
\hline B & $\mathbf{T} 1$ & DF1 & $\mathbf{T} 2$ & 口WWP & a TRP & 口TPR & $\mathbf{a} 3$ & DCP & $\mathbf{a}$ T4 \\
\hline T5 & DF3 & HE1 & HE2 & HE3 & DP1 & DP2 & DP3 & $\square \mathrm{DOP}$ & D \\
\hline
\end{tabular}

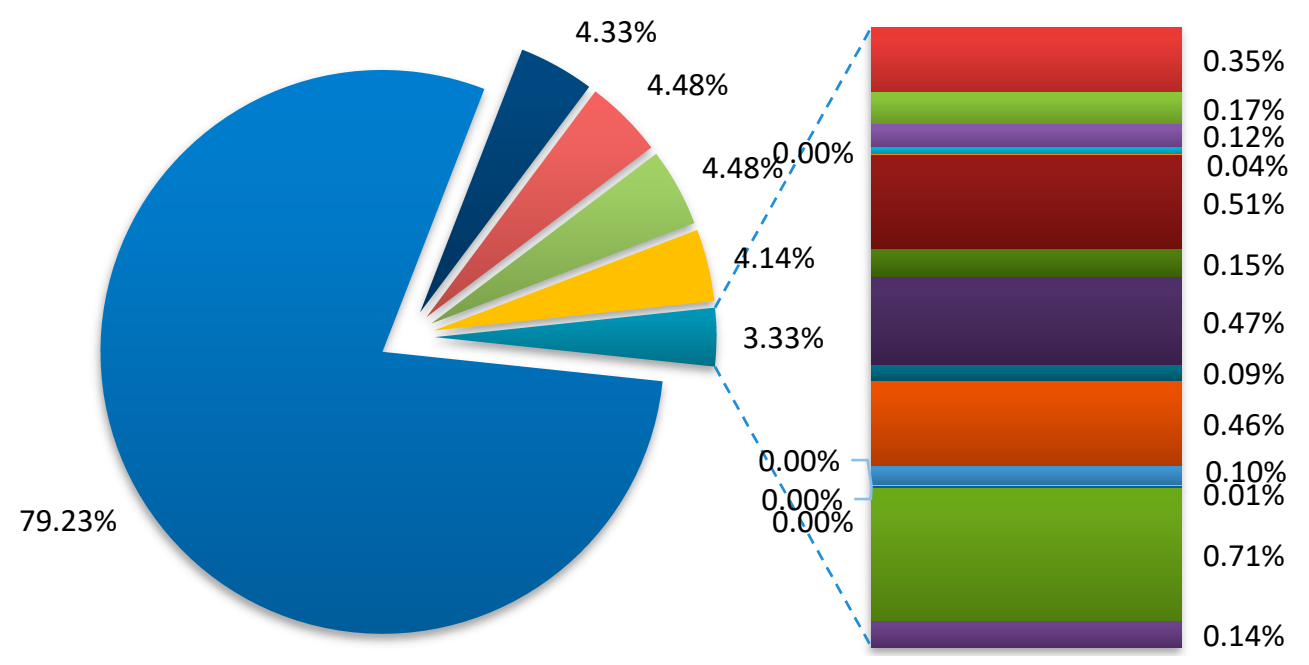

Figure 5. Percentage of each component's exergy destruction of the total exergy destruction.

\subsection{Energy and Exergy Efficiencies}

Figure 6 shows the energy and exergy efficiencies of components and the system. The energy efficiency of the system is $89.72 \%$, while the exergy efficiency is only $10.07 \%$, indicating that the system is rather incomplete and great improvement opportunities are available.

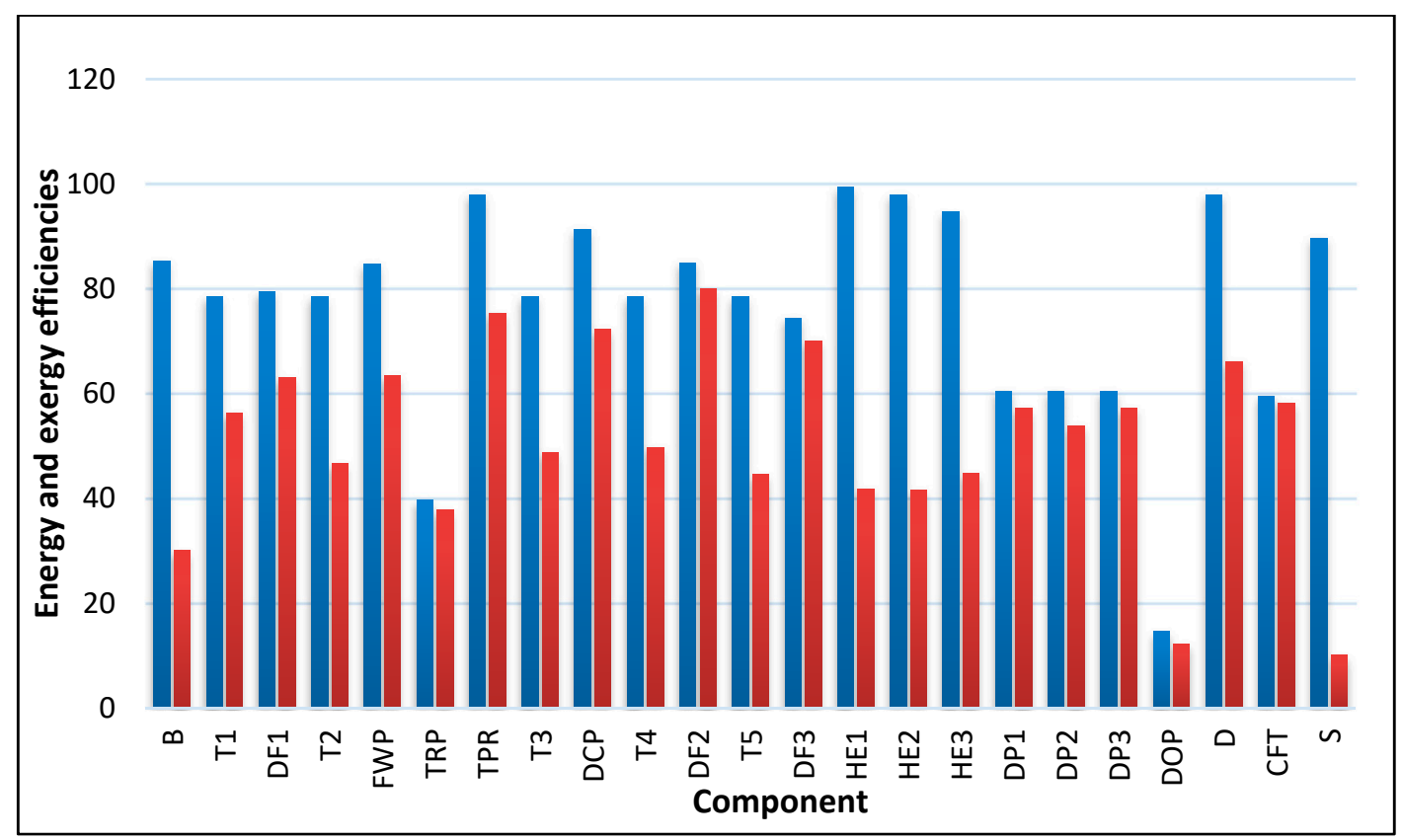

Figure 6. Energy and exergy efficiencies of each component and the system.

The HE1, TPR, deaerator, HE2, and HE3 have high energy efficiencies determined as $99.4 \%, 98 \%$, $98 \%, 97.91 \%$, and $94.63 \%$, while their exergy efficiencies are rather low compared with their energy efficiencies, showing that the temperature differences of heat and mass transfer processes in them may be too large and there are opportunities to be reduced. 
The boiler's energy efficiency is $84.89 \%$, but its exergy efficiency is only $30.04 \%$ due to its significant exergy destruction and exergy loss. When compared with the results obtained from other studies for industrial boilers presented in Table 3, it can be seen that the energy and exergy efficiencies of the boiler in this paper are above the average level, so it is somehow desirable, but when compared with power plant boilers, it seems that the boiler's exergy efficiency is a little lower, indicating that the industrial boilers are inefficient, which are mainly resulted by the small capacity, low parameters, poor manufacturing technology and imperfect operation strategy of industrial boilers [36].

Table 3. Data for energy and exergy efficiencies obtained from other studies.

\begin{tabular}{|c|c|c|c|c|c|c|}
\hline \multirow{2}{*}{$\begin{array}{c}\text { Reference } \\
\text { State }\end{array}$} & \multirow{2}{*}{ Section } & \multicolumn{2}{|c|}{ Energy Efficiency \% } & \multicolumn{2}{|c|}{ Exergy Efficiency \% } & \multirow{2}{*}{ Reference } \\
\hline & & Boiler & Turbine & Boiler & Turbine & \\
\hline \multirow{13}{*}{$\begin{array}{l}298.15 \mathrm{~K} \\
0.10 \mathrm{MPa}\end{array}$} & \multirow{6}{*}{ Industrial } & 72.46 & & 24.89 & & [3] \\
\hline & & 80.80 & & 25.00 & & [3] \\
\hline & & 66.00 & & 26.00 & & [37] \\
\hline & & 82.21 & & 32.77 & & [38] \\
\hline & & 84.65 & & 29.43 & & [15] \\
\hline & & 69.56 & & 38.57 & & [39] \\
\hline & \multirow{7}{*}{ Power plant } & & & 40.84 & 80.10 & \multirow{6}{*}{ [40] } \\
\hline & & & & 36.75 & 85.45 & \\
\hline & & & & 45.47 & 88.60 & \\
\hline & & & & 48.23 & 90.03 & \\
\hline & & & & 36.45 & 84.19 & \\
\hline & & & & 39.00 & 86.16 & \\
\hline & & 84.89 & 78.50 & 30.04 & 49.21 & This work \\
\hline
\end{tabular}

For turbines, their energy efficiencies are designed the same, but their exergy efficiencies are different from each other, and when compared with those in power plants in Table 3 , their averaged exergy efficiencies are much lower, because the steam working in each of them is of different quality. Steam with higher pressure and temperature has more work potential and is more likely to result in higher exergy efficiency. In power plants, the working temperature and pressure of turbines are usually rather higher than industrial ones, thus leading to higher exergy efficiencies.

Energy efficiencies of induced draft fans DF1, DF2 and DF3 are $79.40 \%, 85.00 \%$, and $79.41 \%$, which are tolerable compared with their rated efficiencies of $92.5 \%, 91.2 \%$, and $91.2 \%$, while their exergy efficiencies are $63.00 \%, 79.98 \%$ and $70.01 \%$, respectively, which are mostly due to their exergy destructions, mainly decided by their design considerations. The lowest exergy efficiency of $12.31 \%$ occurs in DOP because it operates under conditions deviating from the design condition caused by improper selection and uses high-quality electricity for pumping water.

\subsection{Exergy Improvement Potential}

Figure 7 shows the exergy balance of the whole system. It depicts the composition of the input exergy and the percentage of the destroyed exergy of every component to the total input exergy of the system. 


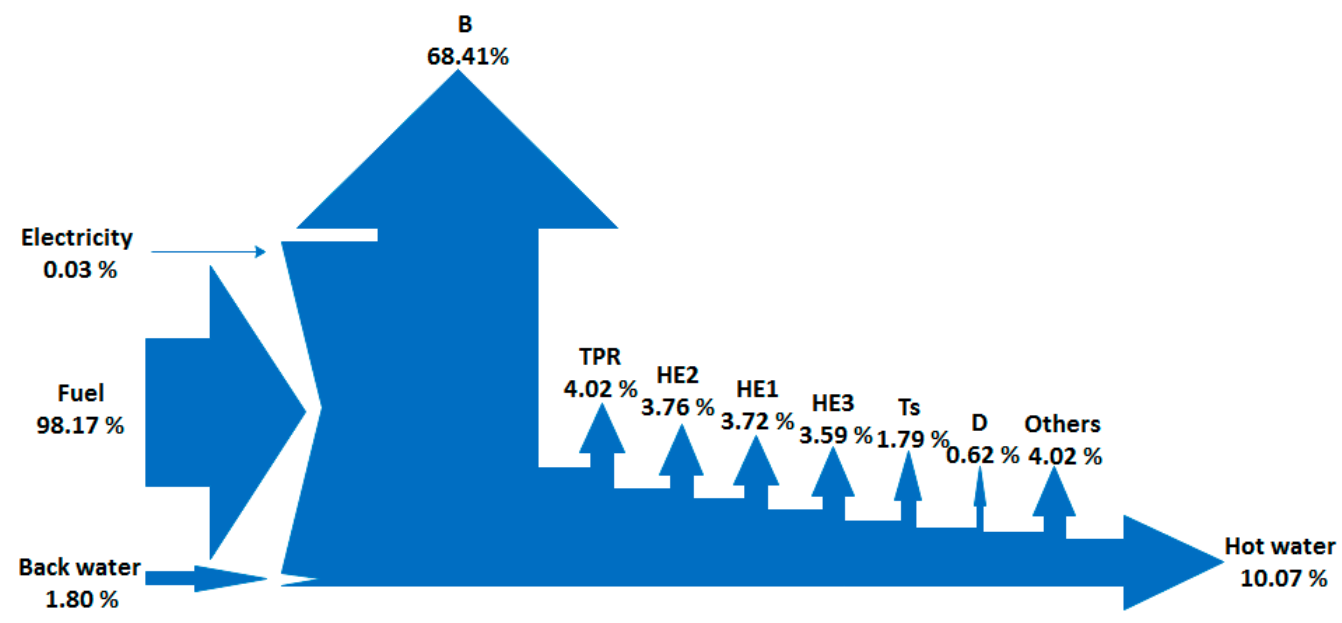

Figure 7. Exergy balance of the whole system.

The fuel exergy is the main input exergy of the system, and $68.41 \%$ of the total input exergy is destroyed in the boiler, followed by HEs, TPR, turbines, and deaerator $(11.07 \%, 4.02 \%, 1.79 \%$, and $0.62 \%$, respectively), and the other components' exergy destruction is $4.01 \%$, so it's assumed that the improvement effort should be made mainly on the boiler, HEs, TPR and turbines. For verifying the assumption, further improvement potential analysis was conducted. As Figure 8 shows, the boiler has the highest exergy improvement potential of $53,895.05 \mathrm{~kW}$, sharing a proportion of $84.65 \%$ of the total exergy improvement potential of $63,664.62 \mathrm{~kW}$. The HEs, TPR, and turbines rank the second, third, and fourth with proportions of $11.22 \%, 1.76 \%$, and $1.61 \%$, so it is clear that the boiler, HEs, TPR and turbines are the main exergy improvement options, accounting for $99.24 \%$ of the total exergy improvement potential. Improvement can be realized by reducing their exergy losses and destructions. For the boiler, taking some measures contributing to chemical reactions such as oxygen enrichment, fresh-air preheating, and decreasing the air-fuel ratio can reduce the exergy destruction [41]. A steam accumulator can help maintain the balance between the steam demand side and the boiler, and Xu [42] found that it could keep the boiler in an iron and steel enterprise working more efficiently and the exergy efficiency could reach $47.97 \%$. Saidur et al. [3] demonstrated that recovering heat energy from flue gas to preheat the feed water could reduce fuel usage of $4.757 \mathrm{~L} / \mathrm{h}$, and the cost of a boiler heat recovery system could be recovered in one year. He also reported that $2-8 \%$ of energy can be saved by enhancing the heat transfer rate of flue gases using nanofluids.

For HEs and TPR, if the quantity and quality of heat and mass transfer at the lowest possible temperature difference could be maintained between the two fluids, and the exergy destruction can thus be greatly reduced. Increasing the surface area of heat transfer may help to cut down the exergy destruction, but it is a design consideration and relates to the economic and spatial limits. In practice, the more reliable way is adopting thermal insulation for equipment [43].

Efforts for exergy improvement of turbines should be focused on their isentropic efficiencies, but operation optimization is also needed. Wang [44] optimized the operation of a turbine's regulating valve based on data mining and succeed in improving the economy of the whole plant unit. Mambro et al. [45] predicted the maximum fluid temperature, the velocity field and the power exchange between fluid and blades when a low-pressure turbine worked at off-design conditions by a multiblock approach. Pumps and induced draft fans are components of minor potential to further exergy utilization, only sharing $0.76 \%$ in the total improvement potential, but they can also be optimized by installing variable speed drives [3]. 

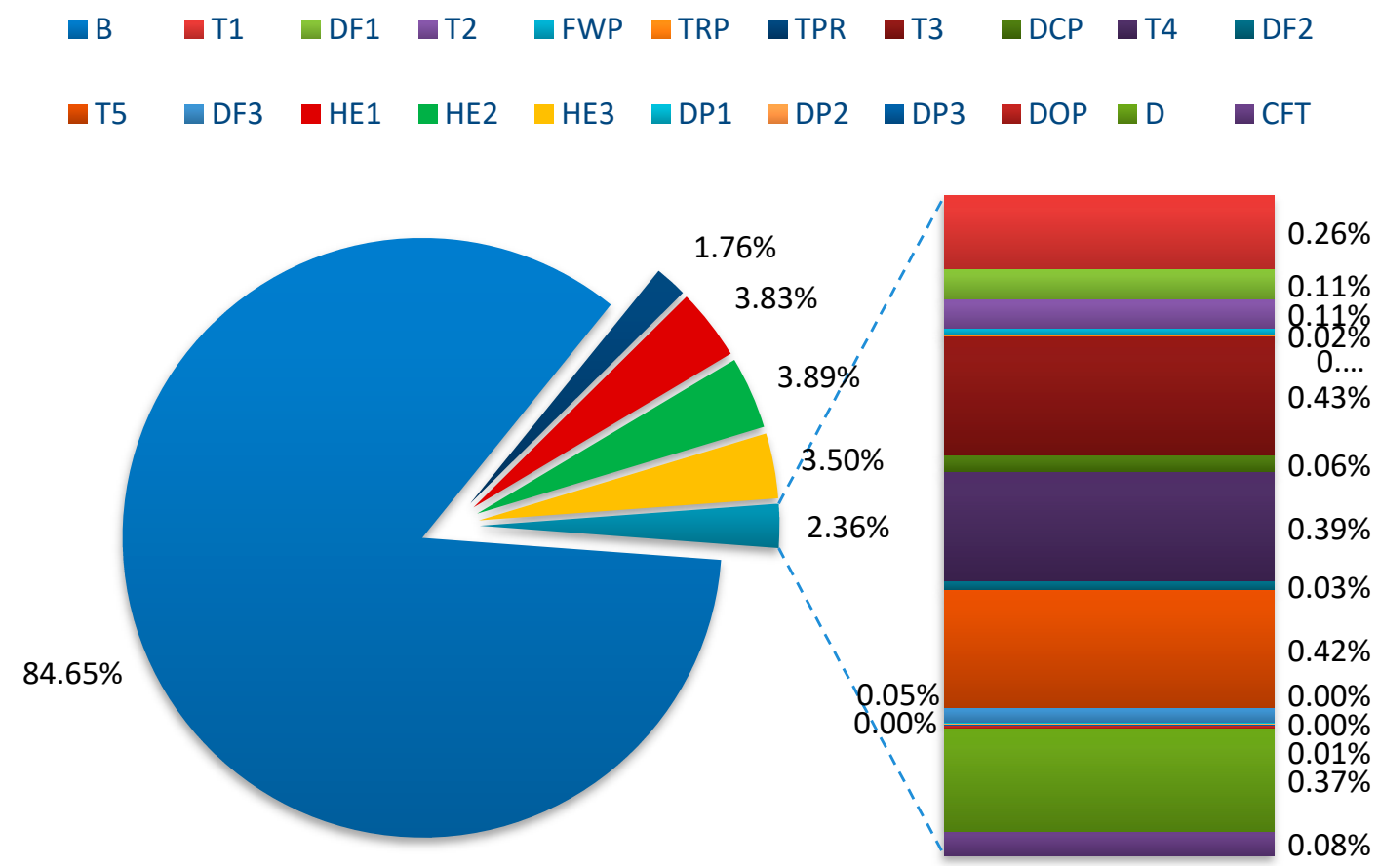

Figure 8. Percentage of each component's exergy improvement potential to the total.

It should be noted that some improvement remedies for one component might result in larger exergy destructions in other components in the system, so the feasibility of improvement measures should be considered from the perspective of the whole system. For heating the returned water of the pipe network, the TPR directly reduces the high-temperature and high-pressure steam to the low-temperature and low-pressure, resulting in its high exergy loss and exergy destruction, which reveals that the energy use process is unreasonable. If the TPR is replaced by a turbine to realize a cascaded utilization of energy, the efficiency of the whole system will be greatly improved, but the global economy and the flexibility of operation need to be reconsidered. What's more, the flue gas temperature at the end of the boiler can reach $150{ }^{\circ} \mathrm{C}$ or higher and can be used as the heat source of a refrigerator, thus the multi-generation of work, cool, heat and power can be achieved by the system. This would be a more efficient way for further energy utilization than a typically combined cooling, heating, and power system $[46,47]$. Biomass energy has great potential utilization value because of its renewability, low carbon dioxide emission, and high hydrogen content [48], and Northeast China is an important grain production base, and rich in biomass resources, so biomass can be considered as the fuel for the system's further transformation.

\subsection{Effect of the Reference Temperature}

The change of reference state has no effect on the analysis based on the first law of thermodynamics. However, the reference state is relevant to the calculation results of the exergy analysis. To find out how significant the influence of the reference state on the results, the reference temperature was varied from 278.15 to $303.15 \mathrm{~K}$ while the reference pressure was kept at $0.10 \mathrm{MPa}$, and the exergy destruction ratio of major component to the total exergy destruction, exergy efficiencies, and exergy improvement potential ratio were plotted in Figures 9-11. Results show that the exergy destruction ratios of major components increase little as the reference temperature rises, and the main exergy destruction source is always the boiler no matter how the reference temperature changes. However, exergy efficiencies of the major components decrease with the reference temperature increases, and the decrement of HEs can get a ratio of $25-31 \%$. What's more, the exergy efficiency of the whole system at $303.15 \mathrm{~K}$ is less than half of that at $303.15 \mathrm{~K}$. Figure 11 indicates that except the exergy improvement of boiler goes down with the reference temperature increases, the HEs, turbines, and TPR, all seem to have more 
improvement potential at the higher reference temperature, but this doesn't change the fact that the boiler has the greatest improvement potential. Although the exergy destruction ratio, exergy efficiency and the exergy improvement potential ratio of the major components in the system changed with the reference state, the main conclusion stayed the same. The main exergy destruction source and improvement part in the system is always the boiler, and this coincides with the previous analysis conducted by Aljundi [49].

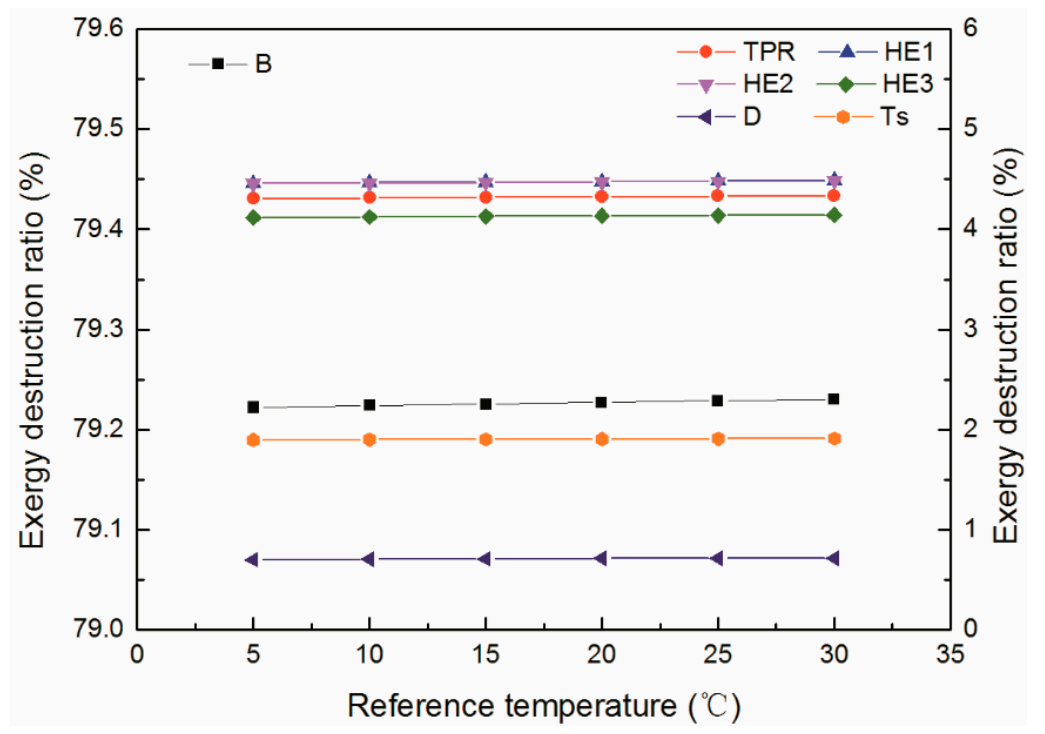

Figure 9. Effect of reference temperature on exergy destruction of major components.

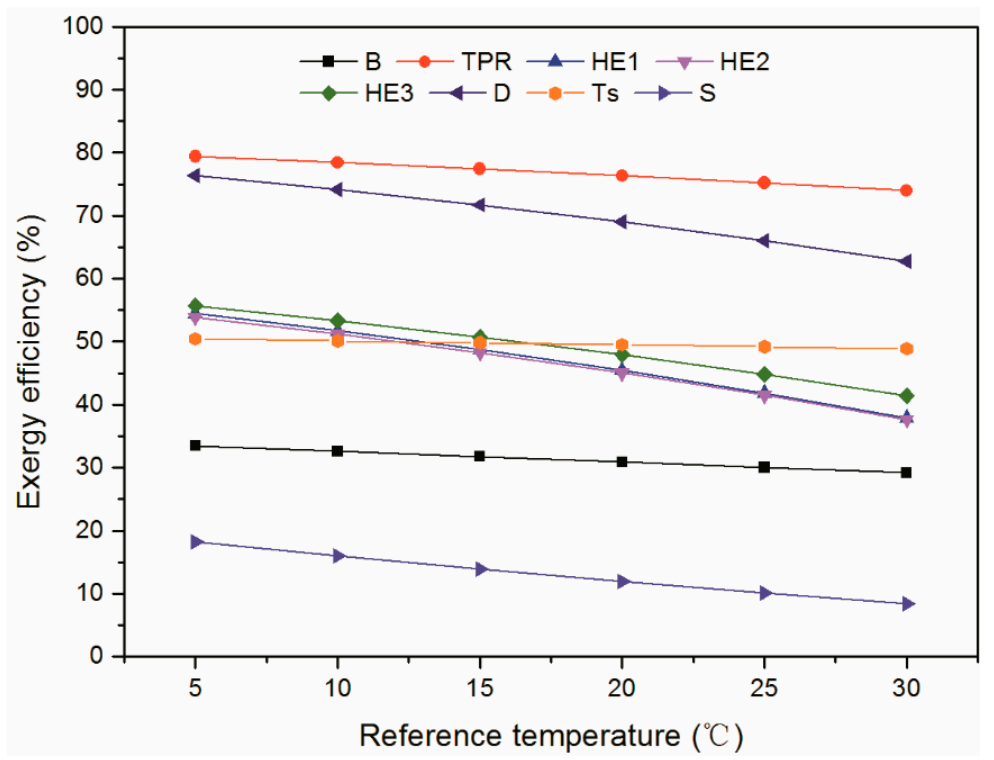

Figure 10. Effect of reference temperature on exergy efficiency of major components. 


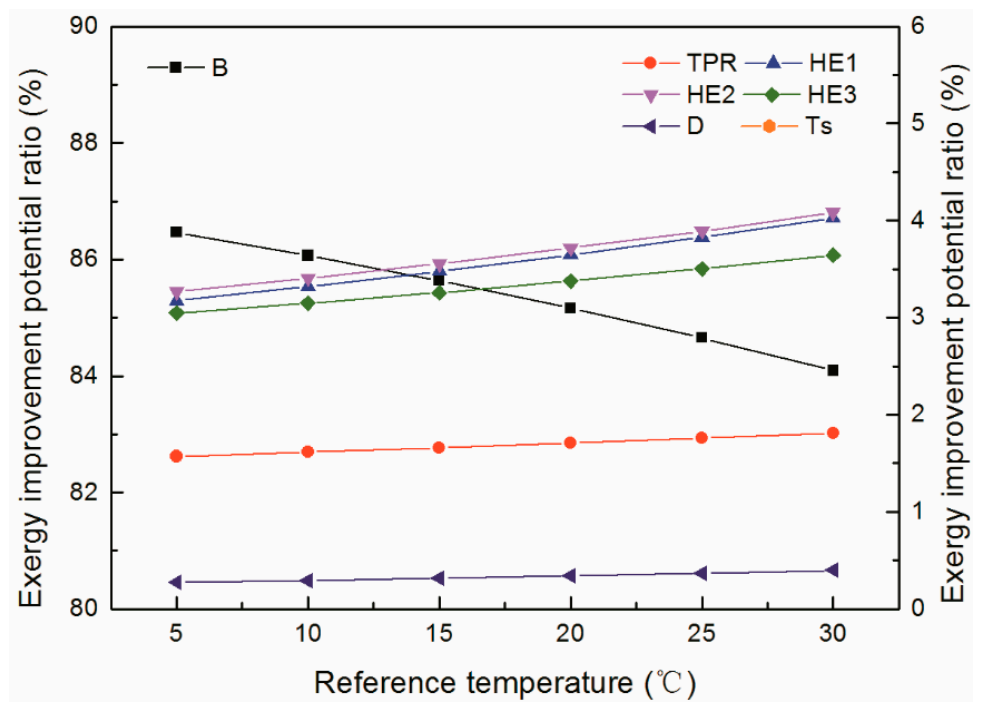

Figure 11. Effect of reference temperature on exergy improvement potential of major components.

\subsection{Economic Analysis}

Table 4 shows the economic analysis of the system under electricity-driving mode and turbinedriving mode using the average electricity price of 0.7173 yuan per $\mathrm{kWh}$ and the on-grid price of 0.3685 yuan per $\mathrm{kWh}$ in 2018 for the general industrial section in Shenyang. It shows if the pumps and draft fans are driven by power, not driven by turbines, then the electricity consumption of the system would be $2121.13 \mathrm{~kW}$ instead of $131.68 \mathrm{~kW}$ on 15 December 2018. The increment of electricity consumption of $1989.45 \mathrm{~kW}$ is accounting for $93.79 \%$ of the total power consumption of the system in this day, which would cost approximately $16,654.08$ yuan more, accounting for $94.65 \%$ of the electricity income under the electricity-driving mode. Thus, the turbine-driving mode of the system can save electricity cost in a great number and it's economical for the heating plant in the long run.

Table 4. Economic analysis of electricity-diving mode and turbine-driving mode.

\begin{tabular}{ccc}
\hline Economic Analysis & Electricity-Driving Mode & Turbine-Driving Mode \\
\hline Power consumption (kW) & 2121.13 & 131.68 \\
Electricity cost (yuan) & $34,343.22$ & 94.46 \\
Electricity income (yuan) & $17,594.69$ & 0.00 \\
Capital saved (yuan) & & $16,654.08$ \\
\hline
\end{tabular}

The above analysis is based on the average electricity price and the fixed on-grid price, but in fact, the electricity price and on-grid price vary with policy and demand. If the fluctuation of electricity price and on-grid price are taken into account, the daily electricity cost saved by the turbine-driving mode is shown in Figure 12. When the on-grid price is fixed, the saved electricity cost by using the turbine-driving mode is increased with the electricity price rises, and when the electricity price equals to the on-grid price, no money is saved by using the turbine-driving mode. When the on-grid price changes from 0.2 yuan $/ \mathrm{kWh}$ to $1.2 \mathrm{yuan} / \mathrm{kWh}$, a cluster of straight lines with the same slope is formed, where the slope is the generated power, and the intercept is revenue from electricity sales. It can be imagined that, no matter what the on-grid price is, as long as the electricity price is equal to the on-grid price, the economy of electricity-driving mode and turbine-driving mode is equivalent. When the electricity price is higher than the on-grid price, the turbine-driving mode is preferred and vice versa. In China, generally, the electricity price is always higher than the on-grid price, so the turbine-driving mode has more advantages. 


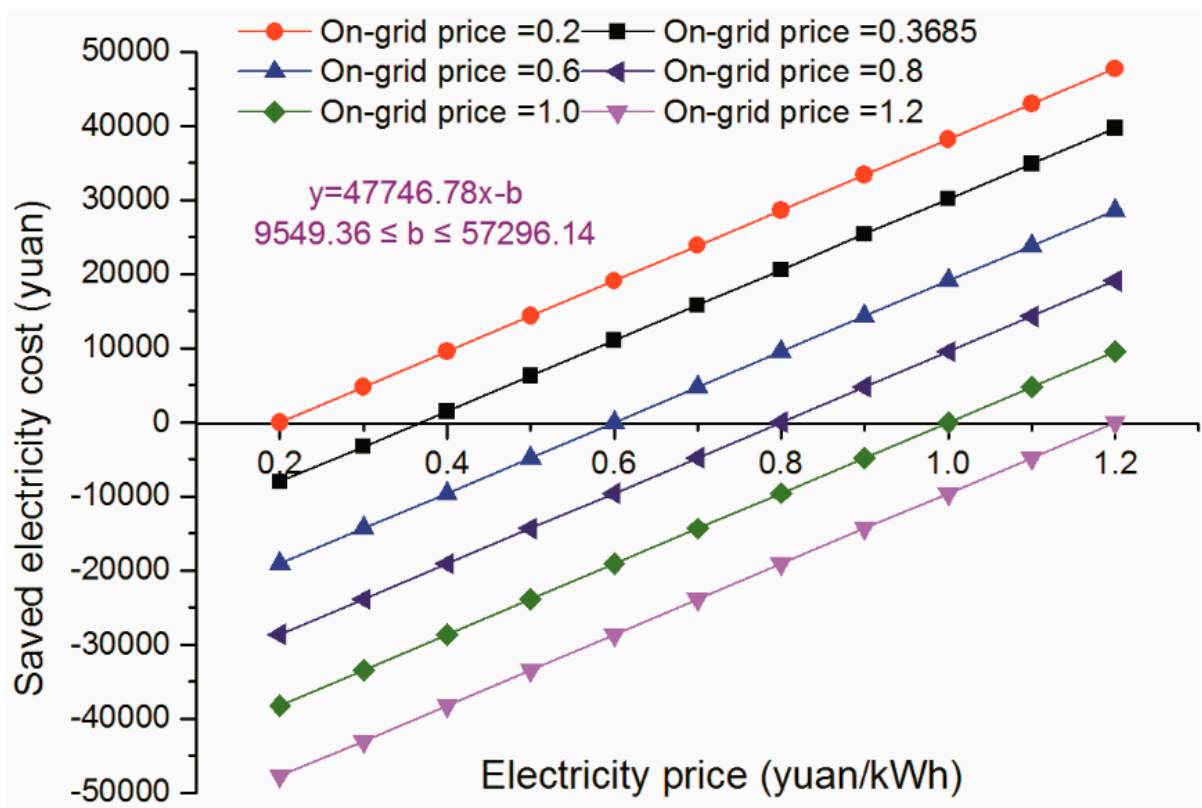

Figure 12. Electricity cost saved by the turbine-driving mode under different.

\section{Conclusions}

In this study, comprehensive energy, exergy and economic analyses of a CHP system with turbine-driving fans and pumps in Northeast China were performed based on operational data. The inefficiencies, sources and improvement potentials of components and the economy of the system are revealed.

The system has total exergy destruction of $93,134.78 \mathrm{~kW}$, and the boiler is the main source of exergy destruction (79.23\%) in the system, followed by HEs, TPR, turbines, and deaerator. The energy and exergy efficiencies of the system are $89.72 \%$ and $10.07 \%$ under the reference state of $25^{\circ} \mathrm{C}$ and $0.10 \mathrm{MPa}$. While the boiler's energy and exergy efficiencies are $84.89 \%$ and $30.04 \%$. The thermodynamic analyses results of the boiler and turbines are compared with other industrial and power plant ones and inefficiencies are indicated. Some advice for the main components and the system is given, including enhancing chemical reactions, recovering heat energy from flue gas, optimizing turbine operation, polygeneration by combining a refrigerator and so on. The effect of reference state on exergy analysis of the major components is also studied, and the main conclusion stayed the same as the reference temperature changes.

The economic analysis revealed that the turbine-driving mode of the CHP system can save electricity power of $1989.45 \mathrm{~kW}$ and electricity cost of 16,654.08 yuan on 15 December 2018. The effect of electricity price and on-grid price on the saved daily electricity cost is investigated and when the electricity price is higher than the on-grid price, the turbine-driving mode is preferred and vice versa. In China, the turbine-driving mode has advantages in saving electricity costs and can be economical in the long run.

Author Contributions: X.L. processed the data, performed the analysis, and wrote the paper. J.G. collected the data from the heating plant, guided through the analysis and acquisited the funding. Y.Z. (Yaning Zhang) and Y.Z. (Yu Zhang) reviewed and edited the paper. Q.D., S.W., and Y.Q. supervised this project. All authors have read and agreed to the published version of the manuscript.

Funding: This research was funded by the National Key Research and Development Program of China grant number 2017YFF0209805.

Conflicts of Interest: The authors declare no conflict of interest. 


\section{Appendix A}

Table A1. Energy balance and energy efficiency of every component.

\begin{tabular}{|c|c|c|}
\hline Component & Energy Balance & Energy Efficiency $(\times \mathbf{1 0 0} \%)$ \\
\hline B & $E n_{1}+E n_{2}=E n_{3}+E n_{4}+Q_{1, \mathrm{~B}}$ & $\eta_{\mathrm{en}, \mathrm{B}}=\frac{\dot{E n_{3}-E n_{1}}}{E n_{2}}$ \\
\hline $\mathrm{T} 1$ & $\dot{E} n_{5}=\dot{E} n_{6}+\dot{W}_{7}+\dot{Q}_{1, \mathrm{~T} 1}$ & $\eta_{\mathrm{en}, \mathrm{T} 1}=\frac{W_{7}}{E n_{5}-E n_{6}}$ \\
\hline DF1 & $\dot{W}_{7}=\dot{P}_{\mathrm{e}, \mathrm{DF} 1}+\dot{Q}_{\mathrm{l}, \mathrm{DF} 1}$ & $\eta_{\mathrm{en}, \mathrm{DF} 1}=\frac{\dot{P}_{\mathrm{e}, \mathrm{DF} 1}}{\dot{W}_{7}}$ \\
\hline $\mathrm{T} 2$ & $\dot{E} n_{10}=\dot{W}_{11}+\dot{E} n_{12}+\dot{Q}_{1, \mathrm{~T} 2}$ & $\eta_{\mathrm{en}, \mathrm{T} 2}=\frac{W_{11}}{E n_{10}-\dot{E n_{12}}}$ \\
\hline FWP & $\dot{W}_{11}+\dot{E} n_{13}=\dot{E} n_{14}+\dot{Q}_{1, \mathrm{FWP}}$ & $\eta_{\mathrm{en}, \mathrm{FWP}}=\frac{E n_{14}-E n_{13}}{W_{11}}$ \\
\hline TRP & $\dot{W}_{15}+\dot{E} n_{16}=\dot{E} n_{17}+\dot{Q}_{1, \mathrm{TRP}}$ & $\eta_{\mathrm{en}, \mathrm{TRP}}=\frac{\dot{E n_{17}-E n_{16}}}{\dot{W}_{15}}$ \\
\hline TPR & $\dot{E} n_{17}+\dot{E} n_{18}=\dot{E} n_{19}+\dot{Q}_{1, \mathrm{TPR}}$ & $\eta_{\mathrm{en}, \mathrm{TPR}}=\frac{E n_{19}}{E n_{17}+E \eta_{19}}$ \\
\hline T3 & $\dot{E n_{20}}=\dot{E} n_{21}+\dot{W}_{22}+\dot{Q}_{1, \mathrm{~T} 3}$ & $\eta_{\mathrm{en}, \mathrm{T} 3}=\frac{W_{22}}{E n_{20}-E n_{21}}$ \\
\hline DCP & $\dot{W}_{22}+E n_{23}=\dot{E n_{24}}+\dot{Q}_{1, \mathrm{DCP}}$ & $\eta_{\mathrm{en}, \mathrm{DCP}}=\frac{E n_{24}-E n_{23}}{\dot{W}_{22}}$ \\
\hline $\mathrm{T} 4$ & $\dot{E} n_{25}=\dot{E} n_{26}+\dot{W}_{27}+\dot{Q}_{1, T 4}$ & $\eta_{\mathrm{en}, \mathrm{T} 4}=\frac{W_{27}}{E n_{25}-E n_{26}}$ \\
\hline DF2 & $\dot{W}_{27}=\dot{P}_{\mathrm{e}, \mathrm{DF} 2}+\dot{Q}_{1, \mathrm{DF} 2}$ & $\eta_{\mathrm{en}, \mathrm{DF} 2}=\frac{\dot{P}_{\mathrm{e}, \mathrm{DF} 2}}{\dot{W}_{27}}$ \\
\hline T5 & $E n_{30}=E n_{31}+W_{32}+\dot{Q}_{1, \mathrm{~T} 5}$ & $\eta_{\mathrm{en}, \mathrm{T} 5}=\frac{\dot{W}_{32}}{E n_{30}-E n_{31}}$ \\
\hline DF3 & $\dot{W}_{32}=\dot{P}_{\mathrm{e}, \mathrm{DF} 3}+\dot{Q}_{\mathrm{l}, \mathrm{DF} 3}$ & $\eta_{\mathrm{en}, \mathrm{DF} 3}=\frac{P_{\mathrm{e}, \mathrm{DF} 3}}{\dot{W}_{32}}$ \\
\hline HE1 & $\dot{E} n_{35}+\dot{E} n_{36}=\dot{E} n_{37}+\dot{E} n_{38}+\dot{Q_{1, H E} 1}$ & $\eta_{\mathrm{en}, \mathrm{HE} 1}=\frac{E n_{38}-E n_{36}}{E n_{35}-E n_{37}}$ \\
\hline HE2 & $\dot{E} n_{39}+E n_{40}=E n_{41}+E n_{42}+Q_{1, \mathrm{HE} 2}$ & $\eta_{\mathrm{en}, \mathrm{HE} 2}=\frac{E n_{42}-E n_{40}}{E n_{39}-E n_{41}}$ \\
\hline HE3 & $E n_{43}+E n_{44}=E n_{45}+E n_{46}+Q_{1, \mathrm{HE} 3}$ & $\eta_{\mathrm{en}, \mathrm{HE} 3}=\frac{E n_{46}-E n_{44}}{E n_{43}-E n_{45}}$ \\
\hline DP1 & $\dot{W}_{47}+E n_{37}=E n_{48}+Q_{1, D P 1}$ & $\eta_{\mathrm{en}, \mathrm{DP} 1}=\frac{E n_{48}-E n_{37}}{\dot{W}_{47}}$ \\
\hline DP2 & $\dot{W}_{49}+\dot{E} n_{41}=\dot{E} n_{50}+\dot{Q}_{1, \mathrm{DP} 2}$ & $\eta_{\mathrm{en}, \mathrm{DP} 2}=\frac{\dot{E n_{50}-E n_{41}}}{\dot{W}_{49}}$ \\
\hline DP3 & $\dot{W}_{51}+\dot{E} n_{45}=\dot{E} n_{52}+\dot{Q}_{1, \mathrm{DP} 3}$ & $\eta_{\mathrm{en}, \mathrm{DP} 3}=\frac{E n_{52}-E n_{45}}{\dot{W}_{51}}$ \\
\hline DOP & $W_{57}+E n_{58}=E n_{56}+Q_{1, \mathrm{DOP}}$ & $\eta_{\mathrm{en}, \mathrm{DOP}}=\frac{E n_{56}-E n_{58}}{\dot{W}_{57}}$ \\
\hline $\mathrm{D}$ & $E n_{54}+E n_{55}+E n_{56}+E n_{59}=E n_{53}+E n_{63}+Q_{1, \mathrm{D}}$ & 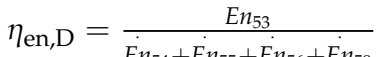 \\
\hline CFT & $E n_{4}=E n_{59}+E n_{60}+\dot{Q} \dot{Q}_{1, \mathrm{CFT}}$ & $\begin{array}{c}E n_{54}+E n_{55}+E n_{56}+E n_{59} \\
\eta_{\mathrm{en}, \mathrm{CFT}}=\frac{E n_{59}}{E n_{4}}\end{array}$ \\
\hline
\end{tabular}




\section{Appendix B}

Table A2. Exergy balance and exergy efficiency of every component.

\begin{tabular}{|c|c|c|}
\hline Component & Exergy Balance & Exergy Efficiency $(\times 100 \%)$ \\
\hline B & $E x_{1}+E x_{2}=E x_{3}+E x_{4}+E x_{1, \mathrm{~B}}+E x_{\mathrm{d}, \mathrm{B}}$ & $\eta_{\mathrm{ex}, \mathrm{B}}=\frac{\dot{E x_{3}-E x_{1}}}{E x_{2}}$ \\
\hline $\mathrm{T} 1$ & $\dot{E x_{5}}=\dot{E x_{6}}+\dot{W}_{7}+\dot{E x_{1, \mathrm{~T} 1}}+\dot{E x_{\mathrm{d}, \mathrm{T} 1}}$ & $\eta_{\mathrm{ex}, \mathrm{T} 1}=\frac{W_{7}}{E x_{5}-E x_{6}}$ \\
\hline DF1 & $\dot{W}_{7}+\dot{E x_{8}}=\dot{E} x_{9}+\dot{E x_{1, D F}}+\dot{E x_{\mathrm{d}, \mathrm{DF} 1}}$ & $\eta_{\mathrm{ex}, \mathrm{DF} 1}=\frac{E x_{9}-E x_{8}}{\dot{W}_{7}}$ \\
\hline $\mathrm{T} 2$ & $\dot{E x_{10}}=\dot{W}_{11}+\dot{E} x_{12}+\dot{E x_{1, \mathrm{~T} 2}}+\dot{E x_{\mathrm{d}, \mathrm{T} 2}}$ & $\eta_{\mathrm{ex}, \mathrm{T} 2}=\frac{\dot{W}_{11}}{E x_{10}-E x_{12}}$ \\
\hline FWP & $\dot{W}_{11}+\dot{E} x_{13}=\dot{E} x_{14}+\dot{E} x_{1, \mathrm{FWP}}+\dot{E} x_{\mathrm{d}, \mathrm{FWP}}$ & $\eta_{\mathrm{ex}, \mathrm{FWP}}=\frac{E x_{14}-E x_{13}}{\dot{W}_{11}}$ \\
\hline TRP & $\dot{W}_{15}+\dot{E} x_{16}=\dot{E} x_{17}+\dot{E} x_{1, \mathrm{TRP}}+\dot{E} x_{\mathrm{d}, \mathrm{TRP}}$ & $\eta_{\mathrm{ex}, \mathrm{TRP}}=\frac{E x_{17}-E x_{16}}{\dot{W}_{15}}$ \\
\hline TPR & $\dot{E} x_{17}+\dot{E x_{18}}=\dot{E} x_{19}+\dot{E x_{1, \mathrm{TPR}}}+\dot{E x_{\mathrm{d}, \mathrm{TPR}}}$ & $\eta_{\mathrm{ex}, \mathrm{TPR}}=\frac{E x_{19}}{E x_{11}+E x_{18}}$ \\
\hline T3 & $E x_{20}=E x_{21}+W_{22}+E x_{1, \mathrm{~T} 3}+E x_{\mathrm{d}, \mathrm{T} 3}$ & $\eta_{\mathrm{ex}, \mathrm{T} 3}=\frac{W_{22}}{E x_{20}-E x_{21}}$ \\
\hline DCP & $\dot{W}_{22}+\dot{E} x_{23}=\dot{E} x_{24}+\dot{E} x_{1, \mathrm{DCP}}+\dot{E} x_{\mathrm{d}, \mathrm{DCP}}$ & $\eta_{\mathrm{ex}, \mathrm{DCP}}=\frac{E x_{24}-E x_{23}}{\dot{W}_{22}}$ \\
\hline $\mathrm{T} 4$ & $\dot{E} x_{25}=E x_{26}+W_{27}+E x_{1, T 4}+E x_{\mathrm{d}, \mathrm{T} 4}$ & $\eta_{\mathrm{ex}, \mathrm{T} 4}=\frac{W_{27}}{E x_{25}-E x_{26}}$ \\
\hline DF2 & $\dot{W}_{27}+\dot{E x_{28}}=\dot{E} x_{29}+\dot{E x_{1, D F 2}}+\dot{E x_{\mathrm{d}, \mathrm{DF} 2}}$ & $\eta_{\mathrm{ex}, \mathrm{DF} 2}=\frac{E x_{29}-E x_{28}}{\dot{W}_{27}}$ \\
\hline $\mathrm{T} 5$ & $\dot{E x_{30}}=\dot{E} x_{31}+\dot{W}_{32}+\dot{E x_{1, \mathrm{~T} 5}}+\dot{E x_{\mathrm{d}, \mathrm{T} 5}}$ & $\eta_{\mathrm{ex}, \mathrm{T} 5}=\frac{\dot{W}_{32}}{E x_{30}-E x_{31}}$ \\
\hline DF3 & $\dot{W}_{32}+\dot{E} x_{33}=\dot{E} x_{34}+\dot{E x_{1, D F 3}}+\dot{E x_{\mathrm{d}, \mathrm{DF} 3}}$ & $\eta_{\mathrm{ex}, \mathrm{DF} 3}=\frac{E x_{34}-E x_{33}}{\dot{W}_{32}}$ \\
\hline HE1 & $\dot{E x_{35}}+\dot{E} x_{36}=\dot{E x_{37}}+\dot{E} x_{38}+\dot{E x_{1, H E 1}}+\dot{E x_{\mathrm{d}, \mathrm{HE} 1}}$ & $\eta_{\text {ex }, \mathrm{HE} 1}=\frac{E x_{38}-E x_{36}}{E x_{35}-E x_{37}}$ \\
\hline HE2 & $\dot{E x_{39}}+\dot{E} x_{40}=\dot{E} x_{41}+\dot{E} x_{42}+\dot{E} x_{1, \mathrm{HE} 2}+\dot{E x_{\mathrm{d}, \mathrm{HE} 2}}$ & $\eta_{\text {ex }, \mathrm{HE} 2}=\frac{E x_{42}-E x_{40}}{E x_{39}-E x_{41}}$ \\
\hline HE3 & $\dot{E} x_{43}+\dot{E} x_{44}=\dot{E x_{45}}+\dot{E x_{46}}+\dot{E} x_{1, \mathrm{HE} 3}+\dot{E x_{\mathrm{d}, \mathrm{HE} 3}}$ & $\eta_{\text {ex }, \mathrm{HE} 3}=\frac{E x_{46}-E x_{44}}{E x_{43}-E x_{45}}$ \\
\hline DP1 & $\dot{W}_{47}+\dot{E x_{37}}=\dot{E} x_{48}+\dot{E} x_{1, \mathrm{DP} 1}+\dot{E} x_{\mathrm{d}, \mathrm{DP} 1}$ & $\eta_{\mathrm{ex}, \mathrm{DP} 1}=\frac{E_{488}-\dot{x}_{37}}{\dot{W}_{47}}$ \\
\hline DP2 & $\dot{W}_{49}+\dot{E} x_{41}=\dot{E} x_{50}+\dot{E} x_{1, \mathrm{DP} 2}+\dot{E} x_{\mathrm{d}, \mathrm{DP} 2}$ & $\eta_{\mathrm{ex}, \mathrm{DP} 2}=\frac{\dot{E} x_{50}-E x_{41}}{\dot{W}_{49}}$ \\
\hline DP3 & $\dot{W}_{51}+\dot{E} x_{45}=\dot{E} x_{52}+\dot{E x_{1, D P} 3}+\dot{E x_{\mathrm{d}, \mathrm{DP} 3}}$ & $\eta_{\mathrm{ex}, \mathrm{DP} 3}=\frac{\dot{E} x_{52}-E x_{45}}{\dot{W}_{51}}$ \\
\hline DOP & $\dot{W}_{57}+\dot{E x_{58}}=\dot{E x_{56}}+\dot{E x_{1, \mathrm{DOP}}}+\dot{E x_{\mathrm{d}, \mathrm{DOP}}}$ & $\eta_{\mathrm{ex}, \mathrm{DOP}}=\frac{\dot{E} x_{56}-E x_{58}}{\dot{W}_{57}}$ \\
\hline $\mathrm{D}$ & $\dot{E x_{54}}+\dot{E x_{55}}+\dot{E x_{56}}+\dot{E x_{59}}=\dot{E x_{53}}+\dot{E x_{63}}+\dot{E x_{1, D}}+\dot{E x_{\mathrm{d}, \mathrm{D}}}$ & $\eta_{\mathrm{ex}, \mathrm{D}}=\frac{\dot{E} x_{53}}{E x_{54}+E x_{55}+E x_{56}+E x_{59}}$ \\
\hline CFT & $E x_{4}=E x_{59}+E x_{60}+E x_{1, \mathrm{CFT}}+E x_{\mathrm{d}, \mathrm{CFT}}$ & $\eta_{\text {ex,CFT }}=\frac{E x_{59}}{E x_{4}}$ \\
\hline
\end{tabular}




\section{Appendix C}

Table A3. Properties of streams at each state number.

\begin{tabular}{|c|c|c|c|c|c|c|c|}
\hline No. & $\begin{array}{c}\text { Pressure } \\
\text { (Mpa) }\end{array}$ & $\begin{array}{l}\text { Temperature } \\
\text { (K) }\end{array}$ & $\begin{array}{l}\text { Fluid } \\
\text { Type }\end{array}$ & $\begin{array}{l}\text { Mass Flow Rate } \\
\left(\mathrm{kg} \cdot \mathrm{s}^{-1}\right)\end{array}$ & $\begin{array}{c}\text { Exergy Rate } \\
\left(\mathrm{kJ} \cdot \mathrm{kg}^{-1}\right)\end{array}$ & $\begin{array}{l}\text { Energy } \\
(\mathbf{k W})\end{array}$ & Exergy $(\mathrm{kW})$ \\
\hline 1 & 1.78 & 373.79 & Water & 36.25 & 36.16 & $15,334.39$ & 1310.68 \\
\hline 2 & 0.10 & 273.15 & Fuel & 6.81 & $16,243.50$ & $105,118.61$ & $110,546.04$ \\
\hline 3 & 1.73 & 579.63 & Steam & 34.43 & 1002.31 & $104,909.94$ & $34,514.53$ \\
\hline 4 & 1.73 & 478.23 & Water & 1.81 & 170.72 & 1586.50 & 309.41 \\
\hline 5 & 1.25 & 562.88 & Steam & 3.25 & 947.78 & 9821.77 & 3079.72 \\
\hline 6 & 0.30 & 454.67 & Steam & 3.25 & 676.44 & 9188.56 & 2198.01 \\
\hline 7 & \multicolumn{5}{|c|}{ Work of T1 } & 497.07 & 497.07 \\
\hline 8 & 0.10 & 388.40 & Flue gas & 82.59 & 15.40 & & 1073.83 \\
\hline 9 & 0.11 & 388.40 & Flue gas & 82.59 & 19.89 & & 1387.00 \\
\hline 10 & 1.24 & 549.18 & Steam & 0.93 & 933.10 & 2769.19 & 863.43 \\
\hline 11 & \multicolumn{5}{|c|}{ Work of T2 } & 111.18 & 111.18 \\
\hline 12 & 0.29 & 460.36 & Steam & 0.93 & 675.63 & 2627.56 & 625.18 \\
\hline 13 & 0.12 & 377.93 & Water & 36.25 & 38.13 & $15,923.40$ & 1382.04 \\
\hline 14 & 1.78 & 378.26 & Water & 36.25 & 40.07 & $16,017.65$ & 1452.51 \\
\hline 15 & \multicolumn{5}{|c|}{ Electric power of TRP } & 94.84 & 94.84 \\
\hline 16 & 0.12 & 377.93 & Water & 1.17 & 38.13 & 516.15 & 44.80 \\
\hline 17 & 1.26 & 378.03 & Water & 1.17 & 39.32 & 517.62 & 46.20 \\
\hline 18 & 1.23 & 566.70 & Steam & 19.17 & 950.12 & $58,103.56$ & $18,210.70$ \\
\hline 19 & 0.30 & 452.95 & Steam & 20.34 & 675.21 & $57,448.75$ & $13,734.92$ \\
\hline 20 & 1.21 & 557.88 & Steam & 3.91 & 938.65 & $11,792.57$ & 3674.05 \\
\hline 21 & 0.28 & 464.30 & Steam & 3.91 & 674.48 & $11,150.68$ & 2640.05 \\
\hline 22 & \multicolumn{5}{|c|}{ Work of T3 } & 503.88 & 503.88 \\
\hline 23 & 0.10 & 298.15 & Water & 1069.72 & 0.00 & $112,245.95$ & 0.00 \\
\hline 24 & 0.44 & 298.16 & Water & 1069.72 & 0.34 & $112,705.93$ & 364.30 \\
\hline 25 & 1.22 & 559.98 & Steam & 3.84 & 942.28 & $11,587.10$ & 3618.86 \\
\hline 26 & 0.30 & 468.10 & Steam & 3.84 & 685.90 & $10,962.90$ & 2634.20 \\
\hline 27 & \multicolumn{5}{|c|}{ Work of T4 } & 490.00 & 490.00 \\
\hline 28 & 0.10 & 388.04 & Flue gas & 90.92 & 15.29 & & 1389.87 \\
\hline 29 & 0.11 & 388.04 & Flue gas & 90.92 & 19.60 & & 1781.74 \\
\hline 30 & 1.23 & 556.35 & Steam & 3.34 & 939.43 & $10,045.66$ & 3136.52 \\
\hline 31 & 0.28 & 470.27 & Steam & 3.34 & 678.92 & 9552.26 & 2266.74 \\
\hline 32 & \multicolumn{5}{|c|}{ Work of T5 } & 387.32 & 387.32 \\
\hline 33 & 0.10 & 386.10 & Flue gas & 62.91 & 14.69 & & 923.87 \\
\hline 34 & 0.11 & 386.10 & Flue gas & 62.91 & 19.00 & & 1195.03 \\
\hline 35 & 0.28 & 452.56 & Steam & 11.00 & 666.01 & $31,063.24$ & 7324.48 \\
\hline 36 & 0.52 & 319.45 & Water & 217.57 & 3.43 & $42,277.94$ & 746.99 \\
\hline 37 & 0.04 & 337.69 & Water & 11.00 & 10.02 & 2971.20 & 110.23 \\
\hline 38 & 0.42 & 350.15 & Water & 217.57 & 17.31 & $70,200.70$ & 3766.89 \\
\hline 39 & 0.28 & 452.37 & Steam & 11.00 & 665.89 & $31,058.95$ & 7323.14 \\
\hline 40 & 0.52 & 319.45 & Water & 216.62 & 3.43 & $42,093.35$ & 743.73 \\
\hline 41 & 0.04 & 330.97 & Water & 11.00 & 6.97 & 2661.84 & 76.63 \\
\hline 42 & 0.41 & 350.15 & Water & 216.62 & 17.32 & $69,896.36$ & 3752.61 \\
\hline 43 & 0.28 & 459.41 & Steam & 11.09 & 670.92 & $31,491.26$ & 7442.83 \\
\hline 44 & 0.52 & 319.40 & Water & 155.52 & 3.43 & $30,188.29$ & 533.76 \\
\hline 45 & 0.04 & 336.89 & Water & 11.09 & 9.62 & 2959.96 & 106.77 \\
\hline 46 & 0.42 & 360.88 & Water & 155.52 & 24.59 & $57,186.83$ & 3823.96 \\
\hline 47 & \multicolumn{5}{|c|}{ Electric power of DP1 } & 10.00 & 10.00 \\
\hline 48 & 0.56 & 337.72 & Water & 11.00 & 10.54 & 2977.25 & 115.95 \\
\hline 49 & \multicolumn{5}{|c|}{ Electric power of DP2 } & 10.00 & 10.00 \\
\hline 50 & 0.56 & 331.00 & Water & 11.00 & 7.46 & 2667.89 & 82.02 \\
\hline 51 & \multicolumn{5}{|c|}{ Electric power of DP3 } & 10.09 & 10.09 \\
\hline 52 & 0.56 & 336.92 & Water & 11.09 & 10.14 & 2966.06 & 112.54 \\
\hline 53 & 0.12 & 377.93 & Water & 37.42 & 38.13 & $16,439.55$ & 1426.84 \\
\hline 54 & 0.28 & 452.56 & Steam & 2.52 & 666.01 & 7121.60 & 1679.22 \\
\hline 55 & 0.56 & 334.60 & Water & 33.09 & 9.06 & 8525.91 & 299.83 \\
\hline 56 & 0.58 & 298.18 & Water & 1.73 & 0.48 & 182.47 & 0.83 \\
\hline 57 & \multicolumn{5}{|c|}{ Electric power of DOP } & 6.75 & 6.75 \\
\hline 58 & 0.10 & 298.15 & Water & 1.73 & 0.00 & 181.48 & 0.00 \\
\hline 59 & 0.12 & 377.93 & Steam & 0.35 & 511.83 & 945.07 & 180.29 \\
\hline 60 & 0.12 & 377.93 & Water & 1.46 & 38.13 & 641.43 & 55.67 \\
\hline 61 & 0.12 & 373.27 & Steam & 0.04 & 511.83 & 100.41 & 19.15 \\
\hline
\end{tabular}




\section{Appendix D}

Table A4. The results of energy and exergy analyses.

\begin{tabular}{ccccccc}
\hline Component & $\begin{array}{c}\text { Energy Loss } \\
\mathbf{( k W )}\end{array}$ & $\begin{array}{c}\text { Energy } \\
\text { Efficiency } \\
\mathbf{( \% )}\end{array}$ & $\begin{array}{c}\text { Exergy Loss } \\
\mathbf{( k W )}\end{array}$ & $\begin{array}{c}\text { Exergy } \\
\text { Destruction } \\
\mathbf{( k W )}\end{array}$ & $\begin{array}{c}\text { Exergy } \\
\text { Efficiency } \\
\mathbf{( \% )}\end{array}$ & $\begin{array}{c}\text { Exergy } \\
\text { Improvement } \\
\text { Potential (kW) }\end{array}$ \\
\hline B & $13,956.56$ & 85.21 & 3243.00 & $73,789.79$ & 30.04 & $53,895.05$ \\
T1 & 136.14 & 78.5 & 56.36 & 328.28 & 56.38 & 167.80 \\
DF1 & 102.4 & 79.4 & 23.8 & 160.11 & 49.46 & 92.95 \\
T2 & 30.45 & 78.5 & 12.46 & 114.6 & 46.67 & 67.80 \\
FWP & 16.94 & 84.77 & 3.58 & 37.13 & 63.38 & 14.91 \\
TRP & 2.23 & 39.69 & 0.92 & 1.39 & 37.8 & 1.43 \\
TPR & 1172.42 & 98 & 486.78 & 4035.2 & 75.23 & 1120.03 \\
T3 & 138.01 & 78.5 & 56.72 & 473.4 & 48.73 & 271.80 \\
DCP & 43.9 & 91.29 & 0 & 139.58 & 72.30 & 38.67 \\
T4 & 134.2 & 78.5 & 57.18 & 437.49 & 49.76 & 248.51 \\
DF2 & 73.49 & 85 & 17.02 & 81.1 & 62.78 & 36.52 \\
T5 & 106.08 & 78.5 & 57.06 & 425.4 & 44.53 & 267.62 \\
DF3 & 99.12 & 74.41 & 22.58 & 93.58 & 54.96 & 52.32 \\
HE1 & 169.28 & 99.4 & 18.53 & 4175.82 & 41.86 & 2438.59 \\
HE2 & 594.1 & 97.91 & 65.04 & 4172.6 & 41.52 & 2478.1 \\
HE3 & 1532.76 & 94.63 & 189.23 & 3856.63 & 44.85 & 2231.3 \\
DP1 & 3.95 & 60.49 & 0.46 & 3.82 & 57.21 & 1.83 \\
DP2 & 3.95 & 60.49 & 0.39 & 4.22 & 53.93 & 2.12 \\
DP3 & 3.99 & 60.47 & 0.46 & 3.86 & 57.19 & 1.85 \\
DOP & 5.76 & 14.61 & 0 & 5.92 & 12.31 & 5.19 \\
D & 235.1 & 98 & 49.63 & 663.72 & 66.05 & 242.17 \\
CFT & 0 & 59.57 & 0 & 129.12 & 58.27 & 53.89 \\
Total & $18,560.83$ & 89.72 & 4361.20 & $93,132.76$ & 10.07 & $63,730.45$ \\
\hline
\end{tabular}

\section{References}

1. Hepbasli, A.; Erbay, Z.; Icier, F.; Colak, N.; Hancioglu, E. A review of gas engine driven heat pumps (GEHPs) for residential and industrial applications. Renew. Sust. Energy Rev. 2009, 13, 85-99. [CrossRef]

2. Kaushik, S.C.; Reddy, V.S.; Tyagi, S.K. Energy and exergy analyses of thermal power plants: A review. Renew. Sust. Energy Rev. 2011, 15, 1857-1872. [CrossRef]

3. Saidur, R.; Ahamed, J.U.; Masjuki, H.H. Energy, exergy and economic analysis of industrial boilers. Energy Policy 2010, 38, 2188-2197. [CrossRef]

4. Zhang, Q.; Yi, H.; Yu, Z.; Gao, J.; Wang, X.; Lin, H.; Shen, B. Energy-exergy analysis and energy efficiency improvement of coal-fired industrial boilers based on thermal test data. Appl. Therm. Eng. 2018, 144, 614-627. [CrossRef]

5. Koroglu, T.; Sogut, O.S. Conventional and advanced exergy analyses of a marine steam power plant. Energy 2018, 163, 392-403. [CrossRef]

6. Elhelw, M.; Al Dahma, K.S.; el Hamid Attia, A. Utilizing exergy analysis in studying the performance of steam power plant at two different operation mode. Appl. Therm. Eng. 2019, 150, 285-293. [CrossRef]

7. Ahmadi, G.R.; Toghraie, D. Energy and exergy analysis of Montazeri Steam Power Plant in Iran. Renew. Sustain. Energy Rev. 2016, 56, 454-463. [CrossRef]

8. Xu, C.; Li, X.; Xu, G.; Xin, T.; Yang, Y.; Liu, W.; Wang, M. Energy, exergy and economic analyses of a novel solar-lignite hybrid power generation process using lignite pre-drying. Energy Convers. Manag. 2018, 170, 19-33. [CrossRef]

9. Menberg, K.; Heo, Y.; Choi, W.; Ooka, R.; Choudhary, R.; Shukuya, M. Exergy analysis of a hybrid groundsource heat pump system. Appl. Energy 2017, 204, 31-46. [CrossRef]

10. Vakilabadi, M.A.; Bidi, M.; Najafi, A.F.; Ahmadi, M.H. Exergy analysis of a hybrid solar-fossil fuel power plant. Energy Sci. Eng. 2019, 7, 146-161. [CrossRef]

11. Zhang, C.; Sun, J.; Lubell, M.; Qiu, L.; Kang, K. Design and simulation of a novel hybrid solar-biomass energy supply system in northwest China. J. Clean. Prod. 2019, 233, 1221-1239. [CrossRef] 
12. Koroneos, C.J.; Fokaides, P.A.; Christoforou, E.A. Exergy analysis of a $300 \mathrm{MW}$ lignite thermoelectric power plant. Energy 2014, 75, 304-311. [CrossRef]

13. Guo, Z.; Wang, Q.; Fang, M.; Luo, Z.; Cen, K. Thermodynamic and economic analysis of polygeneration system integrating atmospheric pressure coal pyrolysis technology with circulating fluidized bed power plant. Appl. Energy 2014, 113, 1301-1314. [CrossRef]

14. Ahmadi, G.; Toghraie, D.; Akbari, O. Energy, exergy and environmental (3E) analysis of the existing CHP system in a petrochemical plant. Renew. Sust. Energy Rev. 2019, 99, 234-242. [CrossRef]

15. Gürtürk, M.; Oztop, H.F. Exergy analysis of a circulating fluidized bed boiler cogeneration power plant. Energy Convers. Manag. 2016, 120, 346-357. [CrossRef]

16. Karellas, S.; Braimakis, K. Energy-exergy analysis and economic investigation of a cogeneration and trigeneration ORC-VCC hybrid system utilizing biomass fuel and solar power. Energy Convers. Manag. 2016, 107, 103-113. [CrossRef]

17. Ozdil, N.F.T.; Tantekin, A.; Erbay, Z. Energy and exergy analyses of a fluidized bed coal combustor steam plant in textile industry. Fuel 2016, 183, 441-448. [CrossRef]

18. Zeng, Z.; Hong, M.; Li, J.; Man, Y.; Liu, H.; Li, Z.; Zhang, H. Integrating process optimization with energy-efficiency scheduling to save energy for paper mills. Appl. Energy 2018, 225, 542-558. [CrossRef]

19. Zhao, H.; Lin, B. Will agglomeration improve the energy efficiency in China's textile industry: Evidence and policy implications. Appl. Energy 2019, 237, 326-337. [CrossRef]

20. Mojarab Soufiyan, M.; Dadak, A.; Hosseini, S.S.; Nasiri, F.; Dowlati, M.; Tahmasebi, M.; Aghbashlo, M. Comprehensive exergy analysis of a commercial tomato paste plant with a double-effect evaporator. Energy 2016, 111, 910-922. [CrossRef]

21. Mojarab Soufiyan, M.; Aghbashlo, M. Application of exergy analysis to the dairy industry: A case study of yogurt drink production plant. Food Bioprod. Process. 2017, 101, 118-131. [CrossRef]

22. Mojarab Soufiyan, M.; Aghbashlo, M.; Mobli, H. Exergetic performance assessment of a long-life milk processing plant: A comprehensive survey. J. Clean. Prod. 2017, 140, 590-607. [CrossRef]

23. Kubule, A.; Zogla, L.; Rosa, M. Resource and Energy Efficiency in Small and Medium Breweries. Energy Procedia 2016, 95, 223-229. [CrossRef]

24. Hepbasli, A. A review on energetic, exergetic and exergoeconomic aspects of geothermal district heating systems (GDHSs). Energy Convers. Manag. 2010, 51, 2041-2061. [CrossRef]

25. Ozgener, L.; Hepbasli, A.; Dincer, I. Energy and exergy analysis of the Gonen geothermal district heating system, Turkey. Geothermics 2005, 34, 632-645. [CrossRef]

26. Li, H.; Svendsen, S. Energy and exergy analysis of low temperature district heating network. Energy 2012, 45, 237-246. [CrossRef]

27. Ozgener, L.; Ozgener, O. Monitoring of energy exergy efficiencies and exergoeconomic parameters of geothermal district heating systems (GDHSs). Appl. Energy 2009, 86, 1704-1711. [CrossRef]

28. Zhu, L. Analysis of Market Status and Development Trend of CHP Industry in 2018. Available online: https://www.qianzhan.com/analyst/detail/220/190104-9eb67de3.html (accessed on 4 January 2019).

29. National Development and Reform Commission. 13th Five Year Plan for Electric Power Development; National Energy Administration: Beijing, China, 2016. (In Chinese)

30. Heberle, F.; Brüggemann, D. Exergy based fluid selection for a geothermal Organic Rankine Cycle for combined heat and power generation. Appl. Therm. Eng. 2010, 30, 1326-1332. [CrossRef]

31. Kanoglu, M.; Dincer, I. Performance assessment of cogeneration plants. Energy Convers. Manag. 2009, 50, 76-81. [CrossRef]

32. Wang, J.; Yang, Y. Energy, exergy and environmental analysis of a hybrid combined cooling heating and power system utilizing biomass and solar energy. Energy Convers. Manag. 2016, 124, 566-577. [CrossRef]

33. Al-Sulaiman, F.A.; Hamdullahpur, F.; Dincer, I. Greenhouse gas emission and exergy assessments of an integrated organic Rankine cycle with a biomass combustor for combined cooling, heating and power production. Appl. Therm. Eng. 2011, 31, 439-446. [CrossRef]

34. Khaljani, M.; Khoshbakhti Saray, R.; Bahlouli, K. Comprehensive analysis of energy, exergy and exergoeconomic of cogeneration of heat and power in a combined gas turbine and organic Rankine cycle. Energy Convers. Manag. 2015, 97, 154-165. [CrossRef]

35. Szargut, J.; Morris, D.R.; Steward, F.R. Exergy Analysis of Thermal, Chemical, and Metallurgical Processes, 1st ed.; Hemisphere: New York, NY, USA, 1988. 
36. Yin, W.Z.; Qi, J.F.; Yuan, S. The Energy-Saving Status of the Industrial Boilers and Reduce Consumption Measures; Destech Publications: Lancaster, PA, USA, 2015; pp. 2746-2750.

37. Gürtürk, M.; Oztop, H.F.; Hepbaslı, A. Energy and exergy assessments of a perlite expansion furnace in a plaster plant. Energy Convers. Manag. 2013, 75, 488-497. [CrossRef]

38. Terhan, M.; Comakli, K. Energy and exergy analyses of natural gas-fired boilers in a district heating system. Appl. Therm. Eng. 2017, 121, 380-387. [CrossRef]

39. Ohijeagbon, I.O.; Waheed, M.A.; Jekayinfa, S.O. Methodology for the physical and chemical exergetic analysis of steam boilers. Energy 2013, 53, 153-164. [CrossRef]

40. Erdem, H.H.; Akkaya, A.V.; Cetin, B.; Dagdas, A.; Sevilgen, S.H.; Sahin, B.; Teke, I.; Gungor, C.; Atas, S. Comparative energetic and exergetic performance analyses for coal-fired thermal power plants in Turkey. Int. J. Therm. Sci. 2009, 48, 2179-2186. [CrossRef]

41. Gümüş, M.; Atmaca, M. Energy and Exergy Analyses Applied to a CI Engine Fueled with Diesel and Natural Gas. Energy Sour. Part A 2013, 35, 1017-1027. [CrossRef]

42. Xu, N. Study on Evaluation Method of Steam System Energy Efficiency in Iron and Steel Enterprises; Shandong University: Jinan, China, 2014. (In Chinese)

43. Dowlati, M.; Aghbashlo, M.; Mojarab Soufiyan, M. Exergetic performance analysis of an ice-cream manufacturing plant: A comprehensive survey. Energy 2017, 123, 445-459. [CrossRef]

44. Zhu, W. Flow Characteristic Analysis of Turbine Control Valve Based on Data Mining; Zhejiang University: Hangzhou, China, 2019. (In Chinese)

45. Mambro, A.; Galloni, E.; Congiu, F.; Maraone, N. Modelling of low-pressure steam turbines operating at very low flowrates: A multiblock approach. Appl. Therm. Eng. 2019, 158, 1-9. [CrossRef]

46. Wang, Z.; Han, W.; Zhang, N.; Su, B.; Liu, M.; Jin, H. Assessment of off-design performance of a combined cooling, heating and power system using exergoeconomic analysis. Energy Convers. Manag. 2018, 171, 188-195. [CrossRef]

47. Tian, Z.; Niu, J.; Lu, Y.; He, S.; Tian, X. The improvement of a simulation model for a distributed CCHP system and its influence on optimal operation cost and strategy. Appl. Energy 2016, 165, 430-444. [CrossRef]

48. Sun, H.; Feng, D.; Zhao, Y.; Guo, D.; Ma, Y.; Tan, H.; Sun, S. Characteristics of Gas-Liquid-Solid Products in Corn Straw Gasification: Effect of the Char-Tar-H2O Interaction. Energy Fuels 2019, 33, 9974-9984. [CrossRef]

49. Aljundi, I.H. Energy and exergy analysis of a steam power plant in Jordan. Appl. Therm. Eng. 2009, 29, 324-328. [CrossRef]

(C) 2020 by the authors. Licensee MDPI, Basel, Switzerland. This article is an open access article distributed under the terms and conditions of the Creative Commons Attribution (CC BY) license (http://creativecommons.org/licenses/by/4.0/). 